\title{
COVID-19 Vaccines: A Review of the Safety and Efficacy of Current Clinical Trials
}

\author{
Zhi-Peng Yan ${ }^{1, *,+} \mathbb{C}$, Ming Yang ${ }^{2,+}+\mathbb{D}$ and Ching-Lung Lai ${ }^{1, *}$ \\ 1 Department of Medicine, Queen Mary Hospital, The University of Hong Kong, Hong Kong 999077, China \\ 2 Department of Ophthalmology, The University of Hong Kong, Hong Kong 999077, China; hrmeym@hku.hk \\ * Correspondence: u3537821@hku.hk (Z.-P.Y.); hrmelcl@hku.hk (C.-L.L.); \\ Tel.: +852-2255-4252 (C.-L.L.); Fax: +852-2816-2863 (C.-L.L.) \\ + Co-first authors.
}

check for

updates

Citation: Yan, Z.-P.; Yang, M.; Lai, C.-L. COVID-19 Vaccines: A Review of the Safety and Efficacy of Current Clinical Trials. Pharmaceuticals 2021, 14, 406. https://doi.org/10.3390/ ph14050406

Academic Editor: Juan Carlos Saiz

Received: 25 March 2021

Accepted: 18 April 2021

Published: 25 April 2021

Publisher's Note: MDPI stays neutral with regard to jurisdictional claims in published maps and institutional affiliations.

Copyright: (C) 2021 by the authors. Licensee MDPI, Basel, Switzerland. This article is an open access article distributed under the terms and conditions of the Creative Commons Attribution (CC BY) license (https:// creativecommons.org/licenses/by/ $4.0 /)$.

\begin{abstract}
Various strategies have been designed to contain the COVID-19 pandemic. Among them, vaccine development is high on the agenda in spite of the unknown duration of the protection time. Various vaccines have been under clinical trials with promising results in different countries. The protective efficacy and the short-term and long-term side effects of the vaccines are of major concern. Therefore, comparing the protective efficacy and risks of vaccination is essential for the global control of COVID-19 through herd immunity. This study reviews the most recent data of 12 vaccines to evaluate their efficacy, safety profile and usage in various populations.
\end{abstract}

Keywords: COVID-19; vaccine; safety; efficacy; herd immunity

\section{Introduction}

The COVID-19 pandemic is caused by severe acute respiratory syndrome coronavirus 2 (SARS-CoV-2). Up till February 2021 it had infected more than 110 million patients, causing 2.4 million deaths worldwide, according to data recorded by the World Health Organization (WHO) [1].

The prevention and control of the epidemic in 2020, other than treatment of symptomatic patients, has included monitoring of asymptomatic infections, follow-up and monitoring after cure and discharge, close contact tracking, high-risk population screening, and disinfection of the epidemic source, but the only way for the radical control of COVID19 infections is by effective vaccination. Vaccines stimulate the body to produce specific antibodies, with anamnestic response when the body is exposed to this pathogen again.

During 2020, there has been extensive research to look into the use of vaccinations to prevent further transmission of SARS-CoV-2. Globally, several prospective vaccines have been produced and used by the public (Table 1). The protective efficacy and immunogenicity profile of each vaccine is also documented (Table 2).

There are currently two forms of messenger ribonucleic acid (mRNA) vaccines: nonreplicating mRNA (NRM) vaccines and self-amplifying mRNA (SAM) vaccines. The constructed mRNA is formulated into a carrier-usually lipid nanoparticles-to protect them from degradation and promote cellular uptake [2]. After the carrier particles are ingested into the cell, mRNA is released, which is translated by the ribosome to produce the target protein (recognizable antigen) [3]. After the target protein is secreted by the cell, it is rec-ognized by the immune system and stimulates an immune response. 
Table 1. Summary of vaccine trials.

\begin{tabular}{|c|c|c|c|c|c|c|}
\hline Title [Reference] & Clinical Phase & $\begin{array}{l}\text { Population Characteristics of } \\
\text { the Latest Trial }\end{array}$ & Doses & Technology & Immunogenicity & Safety Profile \\
\hline BNT162b1 [4-6] & $1-2$ & $\begin{array}{c}45 \text { adults in } 3 \text { groups: } 10 \mu \mathrm{g} \\
30 \mu \mathrm{g}, 100 \mu \mathrm{g} \\
12 \text { vaccines: } 3 \text { placebo in each } \\
\text { group }\end{array}$ & 2 injections, 21 days apart & $\begin{array}{c}\text { Lipid nanoparticle } \\
\text { nucleoside-modified mRNA } \\
\text { vaccine, encoding the spike } \\
\text { glycoprotein of SARS-CoV-2 }\end{array}$ & $\begin{array}{l}\text { Dose-dependent antibody } \\
\text { response }\end{array}$ & No serious adverse events \\
\hline BNT162b2 [7,8] & $1-3$ & $\begin{array}{l}\text { 43,448 volunteers aged } 16 \text { or } \\
\text { older in total: (1:1 ratio) } \\
21,720 \text { received vaccines } \\
21,728 \text { received placebo }\end{array}$ & $\begin{array}{l}2 \text { injections of } 30 \mu \mathrm{g} \text { doses for } \\
\text { phase } 3,21 \text { days apart }\end{array}$ & $\begin{array}{l}\text { Lipid nanoparticle } \\
\text { nucleoside-modified mRNA } \\
\text { vaccine, encoding the spike } \\
\text { glycoprotein of SARS-CoV-2 }\end{array}$ & $\begin{array}{l}\text { Similar dose-dependent } \\
\text { response as BNT162b }\end{array}$ & No serious adverse events \\
\hline mRNA-1273 [9-11] & $1-3$ & $\begin{array}{c}30,420 \text { adults in total: } \\
\text { (1:1 ratio) } \\
15,210 \text { received vaccines } \\
15,210 \text { received placebo }\end{array}$ & $\begin{array}{l}2 \text { injections of } 100 \mu \mathrm{g} \text { doses, } \\
28 \text { days apart }\end{array}$ & $\begin{array}{l}\text { Lipid nanoparticle capsule of } \\
\text { four lipids, encoding the S-2P } \\
\text { antigen. }\end{array}$ & $\begin{array}{l}100 \% \text { seroconversion rates by } \\
\text { day } 15\end{array}$ & $\begin{array}{l}\text { Similar grade } 3 \text { adverse events } \\
\text { in the placebo group }(1.3 \%) \text { and } \\
\text { the vaccine group }(1.5 \%)\end{array}$ \\
\hline ChAdOx1 nCoV-19 [12-14] & $1-3$ & $\begin{array}{l}23,848 \text { adults randomised 1:1 } \\
\text { ratio to receive ChAdOx1 } \\
\text { nCoV-19 or placebo }\end{array}$ & $\begin{array}{c}2 \text { injections of } 3.5-6.5 \times 10^{10} \\
\text { viral particles per mL, } 28 \text { days } \\
\text { apart }\end{array}$ & $\begin{array}{c}\text { Chimpanzee } \\
\text { adenovirus-vectored vaccine } \\
\text { with SARS-CoV-2 spike } \\
\text { glycoprotein }\end{array}$ & $\begin{array}{l}\text { Median titre of booster-dose } \\
\text { group is more than } 5 \text { times } \\
\text { higher than the single-dose } \\
\text { group. }\end{array}$ & $\begin{array}{l}\text { - } 13 \text { serious adverse events } \\
\text { - None considered related to the } \\
\text { vaccine }\end{array}$ \\
\hline $\begin{array}{l}\text { Ad5-vectored COVID-19 } \\
{[15-17]}\end{array}$ & $1 \& 2$ & $\begin{array}{l}508 \text { adults randomised 2:1:1 to } \\
\text { receive vaccine at the dosage of } \\
1 \times 10^{11}, 5 \times 10^{10} \text {, or placebo }\end{array}$ & 1 injection & $\begin{array}{c}\text { Replication defective } \\
\text { Ad5-vectored vaccine } \\
\text { expressing the spike } \\
\text { glycoprotein of SARS-CoV-2 }\end{array}$ & $\begin{array}{l}\text { Higher antibody GMT in } \\
\text { high-dose group, compared } \\
\text { with medium and low-dose } \\
\text { groups. }\end{array}$ & $\begin{array}{l}\text { - } 25 \text { grade } 3 \text { or above adverse } \\
\text { events } \\
\text { - All resolved within } 3 \text { to } 4 \text { days } \\
\text { without medications }\end{array}$ \\
\hline rAd26-S and rAd5-S $[18,19]$ & $1-3$ & $\begin{array}{l}21,977 \text { adults in total: } \\
16,501 \text { received vaccines } \\
5476 \text { received placebo }\end{array}$ & $\begin{array}{l}2 \text { injections of } 10^{11} \text { viral } \\
\text { particles in } 0.5 \mathrm{~mL} \text { vaccine, } \\
21 \text { days apart }\end{array}$ & $\begin{array}{l}\text { Replication of Ad5-vectored } \\
\text { and Ad-26 vectored vaccine } \\
\text { expressing the gene for } \\
\text { SARS-CoV-2 full-length } \\
\text { glycoprotein S }\end{array}$ & $100 \%$ seroconversion rate & No serious adverse events \\
\hline NVX-CoV2373 [20-22] & $1-3$ & $\begin{array}{l}30,000 \text { adults in total: } \\
\text { Randomised in } 2: 1 \text { ratio to } \\
\text { receive vaccine and saline } \\
\text { placebo }\end{array}$ & $\begin{array}{l}2 \text { injections of } 5 \mathrm{mg} \text { protein } \\
\text { with } 50 \mathrm{mcg} \text { matrix-M } \\
\text { adjuvant, } 21 \text { days apart. }\end{array}$ & $\begin{array}{l}\text { Nanoparticle of trimeric } \\
\text { full-length SARS-CoV-2 spike } \\
\text { glycoproteins and Matrix-M1 } \\
\text { adjuvant }\end{array}$ & $\begin{array}{l}\text { IgG GMT and neutralization } \\
\text { responses exceeding } \\
\text { convalescent serum }\end{array}$ & No serious adverse events \\
\hline $\begin{array}{l}\text { WIV-04 strain inactivated } \\
\text { vaccine [10] }\end{array}$ & $1-2$ & $\begin{array}{c}96 \text { adults randomised 1:1:1:1 to } \\
\text { receive low-dose, } \\
\text { medium-dose, high-dose and } \\
\text { aluminium hydroxide, } \\
\text { respectively }\end{array}$ & $\begin{array}{c}\text { Phase 1: } \\
3 \text { injections on day } 0,28 \text { and } 56 \\
\text { Phase } 2: \\
2 \text { injections on day } 0 \text { and } 14 \text {, or } \\
\text { day } 0 \text { and } 21\end{array}$ & $\begin{array}{l}\text { Isolated from WIV-04 strain } \\
\text { and cultivated in a Verco cell } \\
\text { line, followed by serial } \\
\text { inactivation }\end{array}$ & $\begin{array}{c}100 \% \text { seroconversion rates in } \\
\text { phase } 1 \text { trial and } 85.7 \% \text { in the } \\
\text { phase } 2\end{array}$ & $\begin{array}{c}\text { Mild } \\
\text { injection site pain and fever } \\
(23.4 \%)\end{array}$ \\
\hline BBIBP-CorV $[11,23]$ & $1-2$ & $\begin{array}{c}192 \text { adults: } \\
18-59 \text { years ( } 96 \text { adults) } \\
\geq 60 \text { years }(96 \text { adults). } \\
24 \text { receiving vaccine of } 2 \mu \mathrm{g}, \\
4 \mu \mathrm{g} \text { or } 8 \mu \mathrm{g} \text { on day } 0 \text { and } 28 ; \\
\text { and } 24 \text { receiving placebo. }\end{array}$ & $\begin{array}{c}\text { Phase 1: } \\
2 \text { injections separated } 28 \text { days } \\
\text { Phase } 2: \\
\text { Single-dose }\end{array}$ & $\begin{array}{l}\text { HB02-strain in Verco cell line, } \\
\text { with serial inactivation }\end{array}$ & $\begin{array}{l}\text { - Higher seroconversion with } \\
\text { higher dosage }(8 \mu \mathrm{g}) \text { by day } 14, \\
\text { - Higher neutralizing antibody } \\
\text { GMT in younger adults }\end{array}$ & $\begin{array}{l}\text { One grade } 3 \text { adverse event: } \\
\text { self-limiting fever }\left(>38.5^{\circ} \mathrm{C}\right)\end{array}$ \\
\hline
\end{tabular}


Table 1. Cont.

\begin{tabular}{|c|c|c|c|c|c|c|}
\hline Title [Reference] & Clinical Phase & $\begin{array}{l}\text { Population Characteristics of } \\
\text { the Latest Trial }\end{array}$ & Doses & Technology & Immunogenicity & Safety Profile \\
\hline Coronavac [24] & $1-3$ & $\begin{array}{l}\text { 13,000 adults randomised to } \\
\text { receive vaccine or placebo } \\
\text { (randomisation ratio not } \\
\text { provided) }\end{array}$ & 2 injections, 28 days apart & $\begin{array}{l}\text { Inactivated vaccine from Vero } \\
\text { cell line with SARS-CoV-2 } \\
\text { (CN02 strain) }\end{array}$ & $\begin{array}{l}\text {-High seroconversion rates: } \\
83 \% \text { in the } 3 \mu \mathrm{g} \text { group, } 79 \% \text { in } \\
\text { the } 6 \mu \mathrm{g} \text { group, and } 4 \% \text { in the } \\
\text { placebo group }\end{array}$ & $\begin{array}{l}\text { One case of serious } \\
\text { hypersensitivity with urticaria, } \\
\text { recovered } 3 \text { months after } \\
\text { medical treatment. }\end{array}$ \\
\hline Ad26.COV2.S [25-29] & $1-3$ & $\begin{array}{l}40,000 \text { adults randomised to } \\
\text { receive vaccination or placebo } \\
\text { (randomisation ratio not } \\
\text { provided) }\end{array}$ & $\begin{array}{l}1 \text { injection of } 5 \times 10^{10} \text { virus } \\
\text { particles }\end{array}$ & $\begin{array}{l}\text { replication-incompetent } \\
\text { adenovirus serotype 26 (Ad26) } \\
\text { vector encoding full-length } \\
\text { SARS-CoV-2 spike protein }\end{array}$ & $100 \%$ seroconversion day 57 & $\begin{array}{l}\text { Comparable serious adverse } \\
\text { events in vaccination group } \\
\text { and placebo group. }\end{array}$ \\
\hline BBV152 [30-32] & $1-2$ & $\begin{array}{l}380 \text { participants (aged } \\
\text { 12-65 years) randomised by 1:1 } \\
\text { ratio to receive vaccines of } \\
\text { either } 3 \mu \mathrm{g} \text { or } 6 \mu \mathrm{g} \text {. }\end{array}$ & $\begin{array}{l}2 \text { intramuscular injections on } \\
\text { day } 0 \text { and day } 28\end{array}$ & $\begin{array}{l}\text { whole-virion inactivated } \\
\text { SARS-CoV-2 vaccine } \\
\text { formulated with a toll-like } \\
\text { receptor } 7 / 8 \text { agonist molecule } \\
\text { (IMDG) adsorbed to alum } \\
\text { (Algel) }\end{array}$ & $\begin{array}{l}92.9 \%(95 \% \text { CI } 88.2-96.2) \\
\text { seroconversion rate in the } 3 \mu \mathrm{g} \\
\text { group, and } 98.3 \% \text { (95\% CI } \\
\text { 95.1-99.6) in the } 6 \mu \mathrm{g} \text { group. }\end{array}$ & $\begin{array}{c}\text { Comparable local and systemic } \\
\text { adverse event profile in the } \\
3 \mu \mathrm{g}(9.47 \%) \text { and } 6 \mu \mathrm{\mu g}(11.0 \%) \\
\text { groups. No reported serious } \\
\text { adverse events. }\end{array}$ \\
\hline
\end{tabular}

Table 2. Efficacy and other immune responses of vaccines after completion of vaccinations.

\begin{tabular}{|c|c|c|c|c|}
\hline Title [Reference] & Protective Efficacy & Antigen-Specific IgG GMT Level & Neutralizing Antibody Responses & Cellular Responses \\
\hline BNT162b1 [4-6] & $\begin{array}{l}\text { Similar to BNT162b2 } \\
\text { (actual figure not stated) }\end{array}$ & $\begin{array}{c}-10 \mu \mathrm{g}: 4813 \mathrm{U} / \mathrm{mL} \\
-30 \mu \mathrm{g}: 27,873 \mathrm{U} / \mathrm{mL} \\
\text { - Increase dosage to } 100 \mu \mathrm{g} \text { did not increase } \\
\text { the IgG GMC. } \\
\text { - Lower antigen-binding IgG in participants } \\
\geq 65 \text { years of age }\end{array}$ & $\begin{array}{c}\text { Higher GMT compared to convalescent } \\
\text { serum panel } \\
-10 \mu \mathrm{g}: 1.8 \text {-fold } \\
-30 \mu \mathrm{g}: 2.8 \text {-fold }\end{array}$ & $\begin{array}{l}\text {-Functional } \mathrm{CD} 4^{+} \text {and } \mathrm{CD} 8^{+} \text {responses in all } \\
\text { participants, predominantly Th1 helper } \\
\text { responses. } \\
\text { - The mean fraction of RBD-specific T cells } \\
\text { was higher than convalescent plasma. }\end{array}$ \\
\hline BNT162b2 $[7,8]$ & $94.6 \%(95 \%$ CI 89.9-97.3) & $\begin{array}{c}-10 \mu \mathrm{g}: 5782 \mathrm{U} / \mathrm{mL} \\
-20 \mu \mathrm{g}: 12,464 \mathrm{U} / \mathrm{mL} \\
-30 \mu \mathrm{g}: 9136 \mathrm{U} / \mathrm{mL} \\
\text { - Lower antigen-binding IgG for } \geq 65 \text { years of } \\
\text { age }\end{array}$ & $\begin{array}{l}\text { Higher GMT compared to convalescent } \\
\text { serum panel } \\
\text { 18-55 years: } 1.7-4.6 \text { times } \\
\geq 65 \text { years: } 1.1-2.2 \text { times }\end{array}$ & Not assessed \\
\hline mRNA1273 [9-11] & $94.1 \%(95 \%$ CI $89.3-96.8 ; p<0.001)$ & $\begin{array}{c}-25 \mu \mathrm{g}: 299,751 \mathrm{U} / \mathrm{mL} \\
-100 \mu \mathrm{g}: 782,719 \mathrm{U} / \mathrm{mL} \\
-250 \mu \mathrm{g}: 1,192,154 \mathrm{U} / \mathrm{mL} \\
\end{array}$ & $\begin{array}{l}\text { Neutralizing PRNT } \mathrm{PR}_{80} \text { generally at or above } \\
\text { the value of convalescent serum }\end{array}$ & $\begin{array}{l}\text { - The } 25 \mu \mathrm{g}, 100 \mu \mathrm{g} \text { groups elicited } \mathrm{CD} 4^{+} \mathrm{T} \\
\text { cell responses to Th1 cytokines. } \\
\text { - Minimal Th2 response }\end{array}$ \\
\hline ChadOx1 nCoV-19 [12-14] & $\begin{array}{c}\text { Overall: } \\
70.4 \% \\
(95 \% \text { CI } 54.8-80.6) \\
\text { 2-standard dose: } \\
62.1 \% \\
(95 \% \text { CI } 41.0-75.7) \\
\text { Low dose + standard dose: } \\
90.0 \% \\
(95 \% \text { CI } 67.4-97.0)\end{array}$ & $\begin{array}{l}\text { - Antigen-specific antibody peaked at day } 28 \\
\text { with } 157 \mathrm{GMEU} \\
\text { - Antigen specific IgG on day } 28 \text { decreased } \\
\text { with increasing age: } \\
\text { 18-55 years: } 6439 \mathrm{U} / \mathrm{mL} ; \\
\text { 56-69 years: } 4553 \mathrm{U} / \mathrm{mL} ; \text { and } \geq 70 \text { years: } 3565 \\
\mathrm{U} / \mathrm{mL}\end{array}$ & $\begin{array}{l}91 \% \text { and } 100 \% \text { participants achieved } \mathrm{PRNT}_{80} \\
\text { responses in one-dose and booster-dose } \\
\text { groups, respectively. }\end{array}$ & $\begin{array}{l}\text { - The median SFCs PBPMC in the } \\
\text { standard-dose groups: } \\
\text { 18-55 years: 1187; } \\
\text { 56-69 years: } 797 \\
\text { >70 years: } 977 \\
\text { No significant increase of PBPMC after the } \\
\text { booster vaccination }(p=0.46 \text { from paired } \\
\text { Student's } t \text { test of day } 28 \text { vs. day } 42)\end{array}$ \\
\hline
\end{tabular}


Table 2. Cont

\begin{tabular}{|c|c|c|c|c|}
\hline Title [Reference] & Protective Efficacy & Antigen-Specific IgG GMT Level & Neutralizing Antibody Responses & Cellular Responses \\
\hline Ad5-vectored COVID-19 [15-17] & Not available at the time of writing & $\begin{array}{l}\text { - High-dose: } 1445.8 \text { (95\% CI 935.5-2234.5); } \\
\text { - Medium-dose: } 806 \text { (95\% CI 528.2-1229.9) } \\
\text { - Low-dose: } 615.8(95 \% \text { CI } 405.4-935.5) \\
\text { - Seroconversions of } 97 \%, 94 \% \text { and } 100 \% \text { in } \\
\text { the low-dose, medium-dose and high-dose } \\
\text { groups, respectively. }\end{array}$ & $\begin{array}{c}\text { - High-dose: } \\
34.0 \text { ( } 95 \% \text { CI 22.6-50.1); } \\
\text { - Medium-dose: } \\
16.2 \text { (95\% CI 10.4-25.2); } \\
\text { - Low-dose: } \\
\text { 14.5 ( } 95 \% \text { CI 9.6- } 12.8) \text { ) } \\
\text { - 4-fold increase of anti-RBD IgG in } 50 \%, 50 \% \\
\text { and 75\% in the high-dose, medium-dose and } \\
\text { low-dose groups, respectively. }\end{array}$ & $\begin{array}{c}\text { - The mean SFCs PMPMC: } \\
\text { Low-dose: } \\
20.8 \text { ( } 95 \% \text { CI 12.7-34.0); } \\
\text { Medium-dose: } \\
40.8 \text { (95\% CI 27.6-60.3) and } \\
\text { High-dose: } \\
58.0(95 \% \text { CI 39.1-85.9) } \\
\text { T-cell responses in the high-dose group } \\
\text { significantly higher than the low-dose group } \\
(p<0.001)\end{array}$ \\
\hline rAd26-S and rAd5-S [18,19] & $91.6 \%(95 \%$ CI 85.6-95.2) & $\begin{array}{l}\text { SARS-CoV-2 S1 subunit-specific IgG GMT } \\
\text { was 53,006 with Gam-COVID-Vac and 51,200 } \\
\text { with Gam-COVID-Vac-Lyo }\end{array}$ & $\begin{array}{l}100 \% \text { neutralizing antibody with GMT } 49.25 \\
\text { and } 45.95 \text { by using Gam-COVID-Vac and } \\
51,200 \text { with Gam-COVID-Vac-Lyo, } \\
\text { respectively. }\end{array}$ & $\begin{array}{c}-100 \% \text { increased formation of CD4 } 4^{+} \text {and } \\
\text { CD } 8^{+} \text {cells, and increased IFN- } \gamma \\
\text { - Median cell proliferation: } \\
\text { In frozen formulation: } \\
\text { CD } 4^{+}:+2.5 \% \\
\text { CD } 8^{+}:+1.3 \% \\
\text { In lyophilised formulation: } \\
\text { CD } 4^{+}+1.3 \% \\
\text { CD } 8^{+}:+1.1 \%\end{array}$ \\
\hline NVX-CoV2373 [20-22] & $\begin{array}{c}\text { 89.3\% (95\% CI 75.2-95.4) against B.1.1.7 UK } \\
\text { variant, } \\
\text { 49.4\% (95\% CI 6.1-72.8) against B.1.351 South } \\
\text { Africa variant. }\end{array}$ & $\begin{array}{l}\text { - GMEU increase by } 8(15,319 \text { units in " } 5 \mu \mathrm{gg}+ \\
\text { M1" and } 20,429 \text { units in " } 25 \mu \mathrm{g}+\mathrm{M} 1 \text { "). } \\
\text { - GMEU level higher than in convalescent } \\
\text { serum after second dose }\end{array}$ & $\begin{array}{l}\text { GMFRs } 5 \text { times greater with adjuvant } \\
(5.2 \text { times in "5 } \mu \mathrm{g}+\mathrm{M} 1 \text { " and } 6.3 \text { times in " } 25 \\
\mu \mathrm{g}+\mathrm{M} 1 \text { "). } \\
\text { Second dose with adjuvant resulted in GMT } \\
\text { levels } 4 \text { times greater than those in } \\
\text { symptomatic infections. }\end{array}$ & $\begin{array}{l}\text { Stimulated Th1 phenotype response with } \\
\text { increased IFN- } \gamma, \text { IL-2 and TNF- } \alpha \text {. } \\
\text { Minimal Th2 responses as measured by IL- } 5 \\
\text { and IL-13 cytokines. }\end{array}$ \\
\hline WIV-04 strain inactivated vaccine [10] & Not available at the time of writing. & $\begin{array}{l}\text { - Low-dose: } 415 \text { (95\% CI 288-597); } \\
\text { - Medium-dose: } 349 \text { (95\% CI 258-472); } \\
\text { - High-dose: } 311 \text { (95\% CI 229-422) }\end{array}$ & $\begin{array}{l}\text { Neutralizing antibody levels increased } \\
\text { significantly } 14 \text { days after the second dose, } \\
\text { and the third dose }\end{array}$ & Not assessed \\
\hline BBIBP-CorV $[11,23]$ & Not available at the time of writing. & 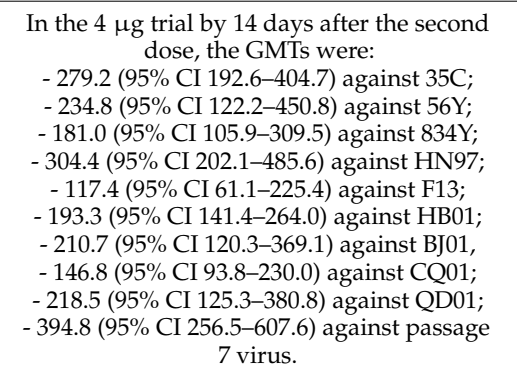 & 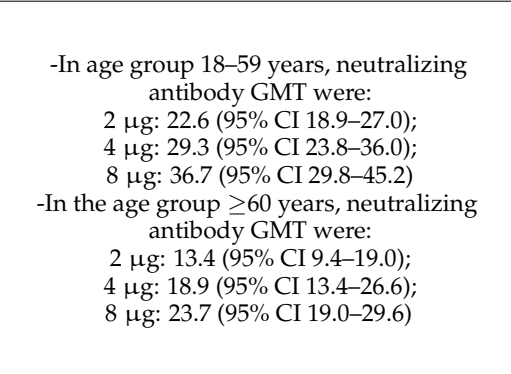 & Not assessed \\
\hline
\end{tabular}


Table 2. Cont.

\begin{tabular}{|c|c|c|c|c|}
\hline Title [Reference] & Protective Efficacy & Antigen-Specific IgG GMT Level & Neutralizing Antibody Responses & Cellular Responses \\
\hline Coronavac [24] & $\begin{array}{c}\text { Brazil: } \\
\text { symptomatic prevention: } \\
50.4 \% \\
\text { - mild cases prevention: } \\
78 \% \\
\text { Severe cases prevention: } \\
100 \% \\
\text { Turkey: } \\
83.5 \% \\
\text { (confidence interval not reported) } \\
\text { Indonesia: } \\
65.3 \% . \\
\text { (confidence interval not reported) }\end{array}$ & $\begin{array}{l}3 \mu \mathrm{gg}: 27.6 \text { (95\% CI } 22.7-33.5) \\
6 \mu \mathrm{g}: 34.5 \text { (95\% CI } 28.5-41.8) \\
\text { Placebo: } 2.3(95 \% \text { CI } 2.0-2.5)\end{array}$ & 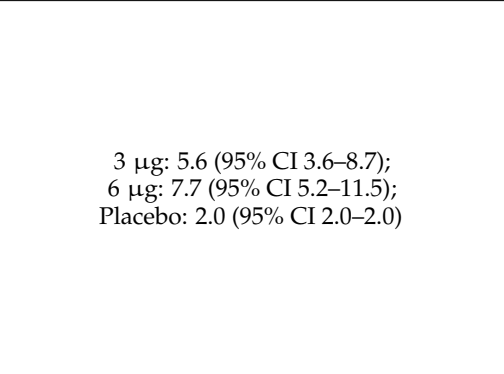 & 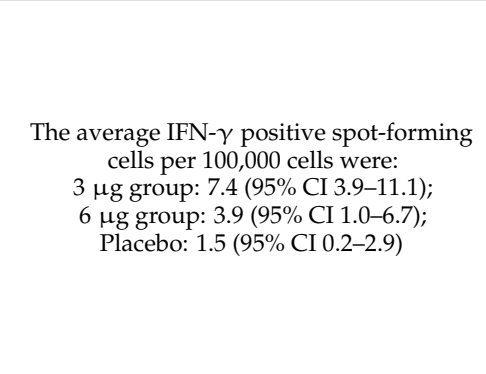 \\
\hline Ad26.COV2.S [25-29] & $\begin{array}{c}\text { Overall: } \\
66.9 \%(95 \% \text { CI } 59.0-73.4) \\
\geq 60 \text { years old } \\
76.3 \%(95 \% \text { CI, } 61.6-86.0)\end{array}$ & $\begin{array}{l}\text { - Ranged from } 2432 \mathrm{U} / \mathrm{mL} \text { to } 5729 \mathrm{U} / \mathrm{mL} \text {. } \\
\text { - The booster immunization on day } 57 \\
\text { increased binding antibody titres } 2.56 \text {-fold } \\
\text { (range 1.58-3.04). }\end{array}$ & $\begin{array}{l}\text { - The GMT of neutralizing antibody ranged } \\
\text { from } 242 \text { to } 449 . \\
\text { - The booster immunization on day } 57 \\
\text { increased neutralizing antibody titres by a } \\
\text { mean of } 4.62 \text {-fold (range: } 3.56-5.68 \text { ). }\end{array}$ & $\begin{array}{c}\text { Stronger } \mathrm{CD} 4^{+} \text {cells response recorded in } \\
\text { younger adults: } \\
18-55 \text { years: } 76 \text { to } 83 \% \\
\geq 65 \text { years: } 60 \text { to } 67 \%\end{array}$ \\
\hline BBV152 [30-32] & Not reported & $\begin{array}{c}-3 \mu \mathrm{g}: 100.9 \text { (95\% CI 74.1-137.4) } \\
-6 \mu \mathrm{g}: 197.0(95 \% \text { CI 155.6-249.4) } \\
(p=0.0041)\end{array}$ & $\begin{array}{c}\text { The neutralizing IgG GMTs at day } 56 \text { were } \\
10,413.9(95 \% \text { CI } 9142.4-11,862.2) \text { in the } 3 \mu \mathrm{g} \\
\text { group; and } 9541.6(95 \% \text { CI } 8245.9-11,041.0) \text { in } \\
\text { the } 6 \mu \text { g group at day } 56 .\end{array}$ & $\begin{array}{l}\text { Strongly biased to a Th1 cell response at day } \\
42 \text {. Th2 response were detected at minimal } \\
\text { level. }\end{array}$ \\
\hline
\end{tabular}

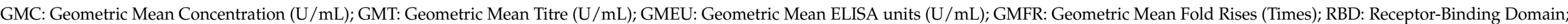

PMPMC: Per Million Peripheral Mononuclear cells; PRNT $_{80}$ : Plaque Reduction Neutralizing Testing assay with detectable $80 \%$ live-virus neutralization. 
DNA vaccines, also known as nucleic acid vaccines or genetic vaccines, have also been studied. DNA vaccines are eukaryotic expression plasmid DNA (sometimes also RNA) that encode immunogens or immu-nogens4. It can enter animals through a certain route, and be transcribed and translated after being taken up by host cells. The antigen protein can stimulate the body to produce two kinds of non-specific and specific immune responses, thereby playing a role in immune protection $[33,34]$. The production process of mRNA is not complicated. The difficulty lies in the fact that mRNA is prone to folding and failure in the absence of protection [35]. Therefore, there is the shortcoming of extremely poor stability. It is questionable whether unstable mRNA is safe for the human body [36]. The comparison between DNA and RNA vaccines is shown in Figure 1.

As of 10 April 2021, the top five countries with vaccination programs are the United States (6.129 million), China (4.052 million), the European Union (2.66 million), the United Kingdom (1.82 million) and India (1.084 million) [37]. Although the implementation of vaccination is one of the important factors to achieve global herd immunity, there is no consensus concerning the superiority of one vaccine over the others in terms of protective efficacy and safety profile, even thigh previous reviews have commented on some of the vaccines [38,39].

To date, there are 86 vaccines under development in clinical phase trials. They are developed with different methods such as protein subunits, inactivated virus, DNA-based vaccine, RNA-based vaccine, viral vectors, and live-attenuated viruses. (see Table 3) [40]. However, many of them are currently in preclinical or phase 1 trials, or without publishing on academic journals at the time of writing. The inclusion criteria of this review are: (1) vaccines that has at least finished their phase 2 clinical trials; and (2) the clinical data of the trial has been published in academic journals and accessible on databases (PubMed, Embase, MedLine, Cochrane) at the time of writing. Exclusion criteria includes: (1) vaccines that are on preclinical phases at the time of writing. (2) vaccines that have not gone through at least phase 2 trials 3) vaccines that have phase 2 trials but have not published their data in academic journals nor accessible on databases (PubMed, Embase, Medline, Cochrane).

This study reviews 12 vaccines in production to evaluate their protective efficacy, safety profile and usage in high risk populations such as children, elderly and patients with co-morbidities. 


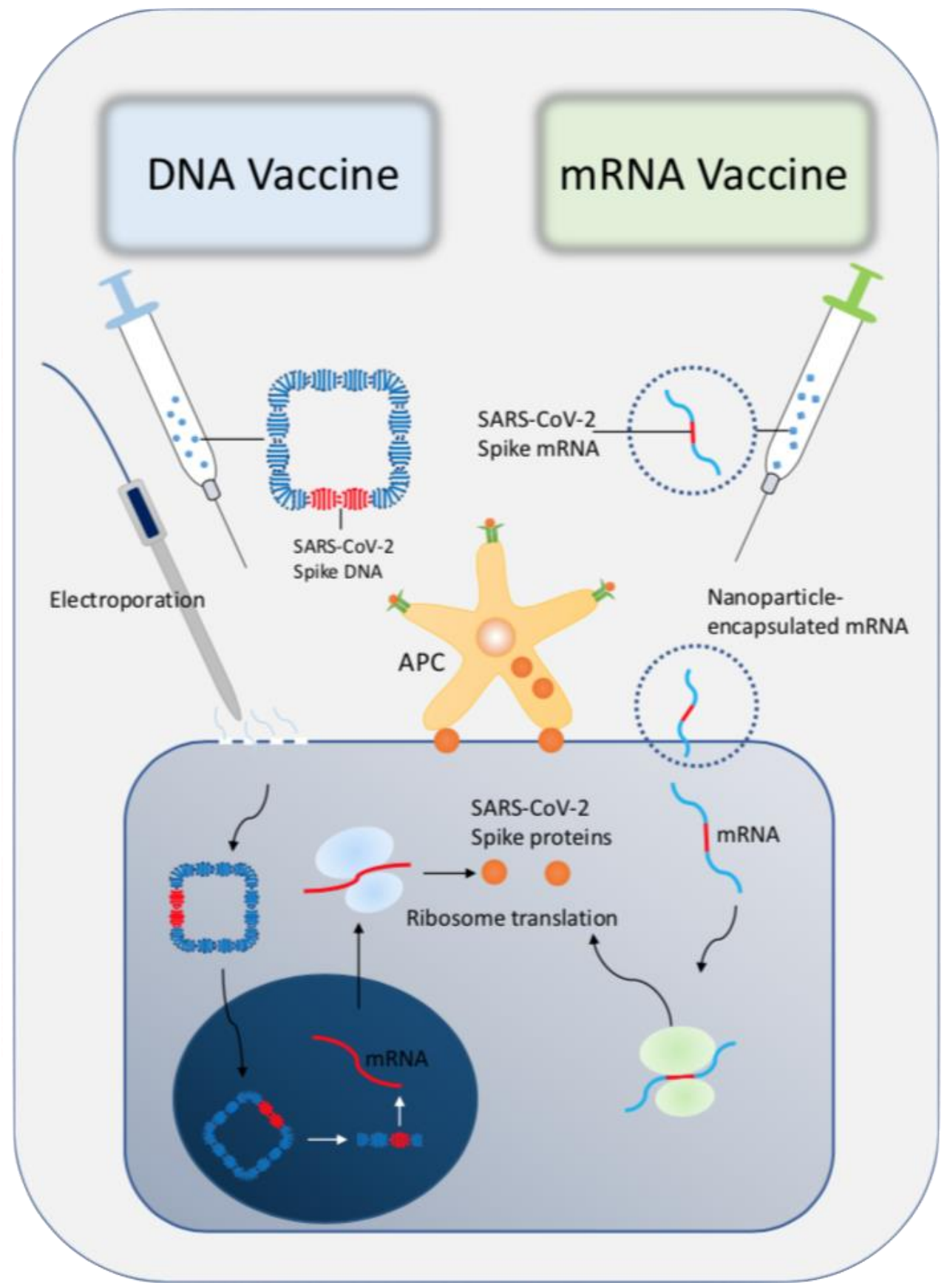

Figure 1. Schematic graph of the comparison between DNA and mRNA vaccine in terms of mechanisms. DNA vaccine is a circle DNA which contains the spike gene of SARS-CoV-2. After electroporation, cell membrane permeation will be increased, allowing DNA enter into cytoplasm thereby reaching to the nuclear. Subsequently, DNA will be translated into mRNA, which will be further translated into SARS-CoV-2 spike proteins and express on cell membrane. Nanoparticle-encapsulated mRNA encoding SARS-CoV-2 antigen will be integrated into cytoplasm. The spike mRNA utilizes ribosome and bases to translate spike proteins, which express on the cell membrane. The membrane spike protein will be recognized by antigen presenting cell (APC) thereby activating immune reaction. 
Table 3. Progress of existing 86 vaccines candidates in clinical trial as at 6th April 2021.

\begin{tabular}{|c|c|c|c|c|c|c|}
\hline Number & Vaccine Platform & Type of Candidate VACCINE & Usage & Developer & Clinical Status & Phase Trials Registration No. \\
\hline 1 & Inactivated virus & $\begin{array}{l}\text { CoronaVac; SARS-CoV-2 } \\
\text { vaccine (inactivated) }\end{array}$ & $\begin{array}{c}2 \text { doses } \\
\text { (day } 0+14) \\
\text { Intramuscular }\end{array}$ & $\begin{array}{l}\text { Sinovac Research and } \\
\text { Development Co., Ltd. }\end{array}$ & Phase 4 & \begin{tabular}{c}
\multicolumn{1}{c}{ Phase $\frac{1}{2}:$} \\
NCT04383574 \\
NCT04352608 \\
NCT04551547 \\
Phase 3: \\
NCT04456595 \\
NCT04508075 \\
NCT04582344 \\
NCT04617483 \\
NCT04651790 \\
NCT04800133 \\
Phase 4: \\
NCT04756830 \\
NCT04747821 \\
NCT04775069 \\
NCT04789356 \\
NCT04754698 \\
NCT04801888
\end{tabular} \\
\hline 2 & Inactivated virus & $\begin{array}{l}\text { Inactivated SARS-CoV-2 } \\
\text { vaccine (Vero cell) }\end{array}$ & $\begin{array}{c}2 \text { doses } \\
\text { (day } 0+21) \\
\text { Intramuscular }\end{array}$ & $\begin{array}{l}\text { Sinopharm + China National } \\
\text { Biotec Group Co + Wuhan } \\
\text { Institute of Biological Products }\end{array}$ & Phase 3 & $\begin{array}{c}\text { Phase } \frac{1}{2}: \\
\text { ChiCTR200031809 } \\
\text { Phase 3: } \\
\text { ChiCTR2000034780 } \\
\text { ChiCTR2000039000 } \\
\text { NCT04510207 } \\
\text { NCT04612972 } \\
\end{array}$ \\
\hline 3 & Inactivated virus & $\begin{array}{l}\text { Inactivated SARS-CoV-2 } \\
\text { vaccine (Vero cell), vaccine } \\
\text { name BBIBP-CorV }\end{array}$ & $\begin{array}{c}2 \text { doses } \\
\text { (day } 0+21) \\
\text { Intramuscular }\end{array}$ & $\begin{array}{l}\text { Sinopharm + China National } \\
\text { Biotec Group Co + Beijing } \\
\text { Institute of Biological Products }\end{array}$ & Phase 3 & $\begin{array}{c}\text { Phase 1/2: } \\
\text { ChiCTR2000032459 } \\
\text { Phase 3: } \\
\text { NCT04560881 } \\
\text { NCT04510207 }\end{array}$ \\
\hline 4 & Viral vector (Non-replicating) & $\begin{array}{l}\text { ChAdOx1-S-(AZD1222) } \\
\text { (Covishield) }\end{array}$ & $\begin{array}{c}2 \text { doses } \\
\text { (day } 0+28) \\
\text { Intramuscular }\end{array}$ & $\begin{array}{l}\text { AstraZeneca + University of } \\
\text { Oxford }\end{array}$ & Phase 4 & $\begin{array}{c}\text { Phase 1: } \\
\text { PACTR202005681895696 } \\
\text { Phase 1/2: } \\
\text { PACTR202006922165132 } \\
\begin{array}{c}\text { NCT04568031 } \\
\text { NCT04444674 }\end{array} \\
\begin{array}{c}\text { NCT04324606 } \\
\text { NCT04684446 }\end{array} \\
\begin{array}{c}\text { ISRCTN15638344 } \\
\text { NCT04760730 } \\
\text { Phase 2 }\end{array} \\
\text { NCT04686773 } \\
\text { ISRCTN69254139 }\end{array}$ \\
\hline
\end{tabular}


Table 3. Cont

\begin{tabular}{|c|c|c|c|c|c|c|}
\hline Number & Vaccine Platform & Type of Candidate VACCINE & Usage & Developer & Clinical Status & Phase Trials Registration No. \\
\hline 4 & Viral vector (Non-replicating) & $\begin{array}{c}\text { ChAdOx1-S-(AZD1222) } \\
\text { (Covishield) }\end{array}$ & $\begin{array}{c}2 \text { doses } \\
\text { (day } 0+28) \\
\text { Intramuscular }\end{array}$ & $\begin{array}{c}\text { AstraZeneca }+ \text { University of } \\
\text { Oxford }\end{array}$ & Phase 4 & $\begin{array}{c}\text { Phase 3: } \\
\frac{\text { ISRCTN89951424 }}{\text { NCT04516746 }} \\
\frac{\text { NCT04540393 }}{\text { NCT04536051 }} \\
\text { EUCTR2020-005226-28-DE } \\
\begin{array}{c}\text { NCT04800133 } \\
\text { Phase 4: }\end{array} \\
\text { NCT04760132 } \\
\text { NCT04775069 }\end{array}$ \\
\hline 5 & Viral vector (Non-replicating) & $\begin{array}{l}\text { Recombinant novel } \\
\text { coronavirus vaccine } \\
\text { (Adenovirus type } 5 \text { vector) }\end{array}$ & $\begin{array}{l}1 \text { dose } \\
\text { Day } 0 \\
\text { Intramuscular }\end{array}$ & $\begin{array}{l}\text { CanSino Biological Inc./Beijing } \\
\text { Institute of Biotechnology }\end{array}$ & Phase 3 & 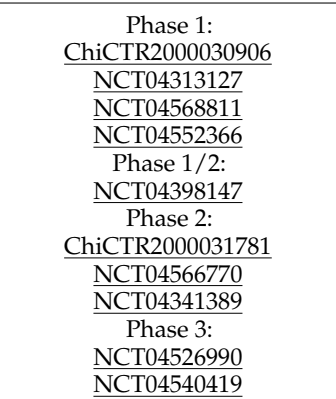 \\
\hline
\end{tabular}


Table 3. Cont

\begin{tabular}{|c|c|c|c|c|c|c|}
\hline Number & Vaccine Platform & Type of Candidate VACCINE & Usage & Developer & Clinical Status & Phase Trials Registration No. \\
\hline 7 & Viral vector (Non-replicating) & Ad26.COV2.S & $\begin{array}{l}1-2 \text { doses } \\
\text { Day } 0 \text { or Day } 0+\text { Day } 56 \\
\text { Intramuscular }\end{array}$ & Janssen Pharmaceutical & Phase 3 & 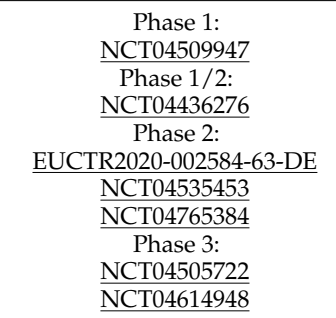 \\
\hline 8 & Protein subunit & $\begin{array}{c}\text { SARS-CoV-2 rS/Matrix } \\
\text { M1-Adjuvant (Full length } \\
\text { recombinant SARS CoV-2 } \\
\text { glycoprotein nanoparticle } \\
\text { vaccine adjuvanted with } \\
\text { Matrix M) }\end{array}$ & $\begin{array}{c}2 \text { doses } \\
\text { (day } 0+21) \\
\text { Intramuscular }\end{array}$ & Novavax & Phase 3 & $\begin{array}{c}\text { Phase 1/2: } \\
\text { NCT04368988 } \\
\text { Phase } 2: \\
\text { NCT04533399 } \\
\text { Phase 3: } \\
\text { NCT04611802 } \\
\text { EUCTR2020-004123-16-GB } \\
\text { NCT04583995 }\end{array}$ \\
\hline 9 & RNA based vaccine & $\begin{array}{l}\text { mRNA -1273 } \\
\text { mRNA-1283 }\end{array}$ & $\begin{array}{c}2 \text { doses } \\
\text { (day } 0+28) \\
\text { Intramuscular }\end{array}$ & $\begin{array}{l}\text { Moderna + National Institute } \\
\text { of Allergy and Infectious } \\
\text { Diseases (NIAID) }\end{array}$ & Phase 4 & $\begin{array}{c}\text { Phase 1: } \\
\text { NCT04283461 } \\
\text { NCT04813796 } \\
\text { Phase 1/2: } \\
\text { NCT04677660 } \\
\text { NCT04712110 } \\
\text { Phase 2: } \\
\text { NCT04405076 } \\
\text { NCT04761822 } \\
\text { Phase 2/3: } \\
\text { NCT04649151 } \\
\text { NCT04796896 } \\
\text { Phase 3: } \\
\text { NCT04470427 } \\
\text { NCT04811664 } \\
\text { NCT04805125 } \\
\text { NCT04806113 } \\
\text { Phase 4: } \\
\text { NCT04760132 } \\
\text { NCT04792567 }\end{array}$ \\
\hline
\end{tabular}


Table 3. Cont.

Number

Vaccine Platform

Type of Candidate VACCINE
Developer

$$
\text { Phase 1: }
$$

ChiCTR2000034825

NCT04816643

Phase 1/2:

NCT04588480

NCT04380701

EUCTR2020-003267-26-DE

Phase 2:
NCT04649021

NCT04761822

Phase 2/3:

NCT04754594

Phase 3:

NCT04368728

$\frac{\text { NCT04713553 }}{\text { NCT0 } 04800133}$

NCT04800133

NCT04805125

NCT0481666

Phase 4:

EUCTR2021-000412-28-BE

EUCTR2021-000412-28-B

NCT04780659

Phase 1

NCT04445194

NCT04636333

Phase $1 / 2$.

NCT04550351

NCT04813562

Phase 2:

NCT04466085

Phase 3: NC104646590

\section{Phase 1}

NCT0444927

NCT04515147

PER-054-20

Phase 2/3:

2 doses

Day $0+$ Day 28

CureVac AG

Phase 3 
Table 3. Cont

\begin{tabular}{|c|c|c|c|c|c|c|}
\hline Number & Vaccine Platform & Type of Candidate VACCINE & Usage & Developer & Clinical Status & Phase Trials Registration No. \\
\hline 13 & Inactivated virus & $\begin{array}{l}\text { SARS-CoV-2 vaccine (Vero } \\
\text { cells) }\end{array}$ & $\begin{array}{c}2 \text { doses } \\
\text { Day } 0+\text { Day } 28 \\
\text { Intramuscular }\end{array}$ & $\begin{array}{l}\text { Institute of Medical Biology }+ \\
\text { Chinese Academy of Medical } \\
\text { Sciences }\end{array}$ & Phase 3 & $\begin{array}{c}\text { Phase 1/2: } \\
\text { NCT04470609 } \\
\text { NCT04412538 } \\
\text { Phase 3: } \\
\text { NCT04659239 } \\
\end{array}$ \\
\hline 14 & Inactivated virus & $\begin{array}{l}\text { QazCovid-in }{ }^{\circledast} \text {-COVID-19 } \\
\text { inactivated vaccine }\end{array}$ & $\begin{array}{c}2 \text { doses } \\
\text { Day } 0+\text { Day } 21 \\
\text { Intramuscular }\end{array}$ & $\begin{array}{l}\text { Research Institute for Biological } \\
\text { Safety Problems, Rep of } \\
\text { Kazakhstan }\end{array}$ & Phase 3 & $\begin{array}{c}\text { Phase } \frac{1}{2}: \\
\text { NCT04530357 } \\
\text { Phase 3: } \\
\text { NCT04691908 } \\
\end{array}$ \\
\hline 15 & DNA based vaccine & INO-4800 + electroporation & $\begin{array}{c}2 \text { doses } \\
\text { Day } 0+\text { Day } 28 \\
\text { Intradermal }\end{array}$ & $\begin{array}{c}\text { Inovio Pharmaceuticals + } \\
\text { International Vaccine Institute + } \\
\text { Advaccine (Suzhou) } \\
\text { Biopharmaceutical Co., Ltd. }\end{array}$ & Phase $2 / 3$ & $\begin{array}{c}\text { Phase 1: } \\
\text { NCT04336410 } \\
\text { ChiCTR2000038152 } \\
\text { Phase 1/2: } \\
\text { NCT04447781 } \\
\text { Phase 2: } \\
\text { ChiCTR2000040146 } \\
\text { Phase 2/3: } \\
\text { NCT04642638 } \\
\end{array}$ \\
\hline 16 & DNA based vaccine & AG0301-COVID19 & $\begin{array}{c}2 \text { doses } \\
\text { Day } 0+\text { Day } 14 \\
\text { Intramuscular }\end{array}$ & $\begin{array}{c}\text { AnGes + Takara Bio + Osaka } \\
\text { University }\end{array}$ & Phase $2 / 3$ & $\begin{array}{c}\text { Phase 1/2: } \\
\text { NCT04463472 } \\
\text { NCT04527081 } \\
\text { jRCT2051200085 } \\
\text { Phase 2/3: } \\
\text { NCT04655625 } \\
\end{array}$ \\
\hline 17 & DNA based vaccine & nCov vaccine & $\begin{array}{c}3 \text { doses } \\
\text { Day } 0+\text { Day } 28+\text { Day } 56 \\
\text { Intradermal }\end{array}$ & Zydus Cadila & Phase 3 & $\begin{array}{c}\text { Phase 1/2: } \\
\text { CTRI/2020/07/026352 } \\
\text { CTRI/2021/03/032051 } \\
\text { Phase 3: } \\
\text { CTRI/2020/07/026352 }\end{array}$ \\
\hline 18 & DNA based vaccine & GX-19N & $\begin{array}{c}2 \text { doses } \\
\text { Day } 0+\text { Day } 28 \\
\text { Intramuscular }\end{array}$ & Genexine Consortium & Phase $\frac{1}{2}$ & $\begin{array}{c}\text { Phase 1/2: } \\
\text { NCT04445389 } \\
\text { NCT04715997 } \\
\end{array}$ \\
\hline 19 & Inactivated virus & $\begin{array}{l}\text { Whole-Virion Inactivated } \\
\text { SARS-CoV-2 Vaccine (BBV152) }\end{array}$ & $\begin{array}{c}2 \text { doses } \\
\text { Day } 0+\text { Day } 14 \\
\text { Intramuscular }\end{array}$ & $\begin{array}{l}\text { Bharat Biotech International } \\
\text { Limited }\end{array}$ & Phase 3 & $\begin{array}{c}\text { Phase } 1 / 2: \\
\text { NCT04471519 } \\
\text { CTRI/2020/07/026300 } \\
\text { CTRI } 2020 / 09 / 027674 \\
\text { Phase } 3 \\
\text { NCT04641481; CTRI } 2020 / 11 / 028976 \\
\end{array}$ \\
\hline 20 & Protein subunit & KBP-COVID-19 (RBD-based) & $\begin{array}{l}2 \text { doses } \\
\text { Day } 0+\text { Day } 21 \\
\text { Intramuscular }\end{array}$ & Kentucky Bioprocessing Inc. & Phase $1 / 2$ & $\begin{array}{c}\text { Phase 1/2: } \\
\text { NCT04473690 } \\
\end{array}$ \\
\hline
\end{tabular}


Table 3. Cont

\begin{tabular}{|c|c|c|c|c|c|c|}
\hline Number & Vaccine Platform & Type of Candidate VACCINE & Usage & Developer & Clinical Status & Phase Trials Registration No. \\
\hline 21 & Protein subunit & $\begin{array}{l}\text { VAT00002: SARS-CoV-2S } \\
\text { protein with adjuvant }\end{array}$ & $\begin{array}{c}2 \text { doses } \\
\text { Day } 0+\text { Day } 21 \\
\text { Intramuscular }\end{array}$ & Sanofi Pasteur + GSK & Phase 3 & $\begin{array}{c}\text { Phase 1/2: } \\
\text { NCT04537208 } \\
\text { Phase 2: } \\
\text { NCT04762680 } \\
\text { Phase 3: } \\
\text { PACTR202011523101903 } \\
\end{array}$ \\
\hline 22 & RNA based vaccine & ARCT-021 & $\begin{array}{c}2 \text { doses } \\
\text { Day } 0+\text { Day } 21 \\
\text { Intramuscular }\end{array}$ & Arcturus Therapeutics & Phase 2 & $\begin{array}{c}\text { Phase 1/2: } \\
\text { NCT04480957 } \\
\text { Phase 2: } \\
\text { NCT04668339 } \\
\text { NCT04728347 }\end{array}$ \\
\hline 23 & Virus like particle & $\begin{array}{l}\text { RBD SARS-CoV-2 HBsAg VLP } \\
\text { vaccine }\end{array}$ & $\begin{array}{c}2 \text { doses } \\
\text { Day } 0+\text { Day } 28 \\
\text { Intramuscular }\end{array}$ & $\begin{array}{l}\text { Serum Institute of India + } \\
\text { Accelagen Pty + SpyBiotech }\end{array}$ & Phase $1 / 2$ & $\begin{array}{c}\text { Phase 1/2: } \\
\text { ACTRN12620000817943 } \\
\text { ACTRN12620001308987 } \\
\end{array}$ \\
\hline 24 & Inactivated virus & $\begin{array}{l}\text { Inactivated SARS-CoV-2 } \\
\text { vaccine (Vero cell) }\end{array}$ & $\begin{array}{l}2-3 \text { doses } \\
\text { Detailed schedule not specified } \\
\text { Intramuscular }\end{array}$ & $\begin{array}{l}\text { Beijing Minhai Biotechnology } \\
\text { Co }\end{array}$ & Phase 2 & $\begin{array}{c}\text { Phase 1: } \\
\text { NCT04758273 } \\
\text { Phase 2: } \\
\text { NCT04756323 } \\
\end{array}$ \\
\hline 25 & Viral vector (Non-replicating) & $\begin{array}{l}\text { GRAd-COV2 (Replication } \\
\text { defective Simian Adenovirus } \\
\text { (GRAd) encoding S) }\end{array}$ & $\begin{array}{l}1 \text { dose } \\
\text { Day 0 } \\
\text { Intramuscular }\end{array}$ & $\begin{array}{l}\text { ReiThera + Leukocare + } \\
\text { Univercells }\end{array}$ & Phase $2 / 3$ & $\begin{array}{c}\text { Phase 1: } \\
\text { NCT04528641 } \\
\text { Phase } 2 / 3: \\
\text { NCT04791423 } \\
\end{array}$ \\
\hline 27 & Viral vector (Non-replicating) & MVA-SARS-2-S & $\begin{array}{c}2 \text { doses } \\
\text { Day } 0+\text { Day } 28 \\
\text { Intramuscular }\end{array}$ & $\begin{array}{l}\text { University of Munich } \\
\text { (Ludwig-Maximilians) }\end{array}$ & Phase 1 & $\begin{array}{c}\text { Phase 1: } \\
\text { NCT04569383 } \\
\end{array}$ \\
\hline 28 & Protein subunit & $\begin{array}{c}\text { SCB-2019 + AS03 or CpG } 1018 \\
\text { adjuvant plus Alum adjuvant } \\
\text { (Native like Trimeric subunit } \\
\text { Spike Protein vaccine) }\end{array}$ & $\begin{array}{c}2 \text { doses } \\
\text { Day } 0+\text { Day } 21 \\
\text { Intramuscular }\end{array}$ & $\begin{array}{l}\text { Clover Biopharmaceuticals } \\
\text { Inc./GSK/Dynavax }\end{array}$ & Phase $2 / 3$ & $\begin{array}{c}\text { Phase 1: } \\
\text { NCT04405908 } \\
\text { Phase 2/3: } \\
\text { NCT04672395 } \\
\end{array}$ \\
\hline 29 & Protein subunit & $\begin{array}{l}\text { COVAX-19 }{ }^{\circledR} \text { Recombinant } \\
\text { spike protein + adjuvant }\end{array}$ & $\begin{array}{c}2 \text { doses } \\
\text { Day } 0+\text { Day } 21 \\
\text { Intramuscular }\end{array}$ & Vaxine Pty Ltd. & Phase 1 & $\begin{array}{c}\text { Phase 1: } \\
\text { NCT04453852 } \\
\end{array}$ \\
\hline 30 & Protein subunit & $\begin{array}{l}\text { MVC-COV1901 (S-2P protein + } \\
\text { CpG 1018) }\end{array}$ & $\begin{array}{c}2 \text { doses } \\
\text { Day } 0+\text { Day } 28 \\
\text { Intramuscular }\end{array}$ & $\begin{array}{c}\text { Medigen Vaccine Biologics + } \\
\text { Dynavax + National Institute of } \\
\text { Allergy and Infectious Diseases } \\
\text { (NIAID) }\end{array}$ & Phase 2 & $\begin{array}{c}\text { Phase 1: } \\
\text { NCT04487210 } \\
\text { Phase 2: } \\
\text { NCT04695652 } \\
\end{array}$ \\
\hline
\end{tabular}


Table 3. Cont

\begin{tabular}{|c|c|c|c|c|c|c|}
\hline Number & Vaccine Platform & Type of Candidate VACCINE & Usage & Developer & Clinical Status & Phase Trials Registration No. \\
\hline 31 & Protein subunit & $\begin{array}{l}\text { FINLAY-FR1 anti-SARS-CoV-2 } \\
\text { Vaccine (RBD + adjuvant) }\end{array}$ & $\begin{array}{c}2 \text { doses } \\
\text { Day } 0+\text { Day } 28 \\
\text { Intramuscular }\end{array}$ & Instituto Finlay de Vacunas & Phase $1 / 2$ & $\begin{array}{c}\text { Phase } 1: \\
\text { RPCEC00000338 } \\
\text { Phase } 1 / 2: \\
\text { RPCEC00000332 } \\
\end{array}$ \\
\hline 34 & Protein subunit & $\begin{array}{l}\text { RBD (baculovirus production } \\
\text { expressed in Sf9 cells) } \\
\text { Recombinant SARS-CoV-2 } \\
\text { vaccine (Sf9 Cell) }\end{array}$ & $\begin{array}{c}2 \text { doses } \\
\text { Day } 0+\text { Day } 21 \\
\text { Intramuscular }\end{array}$ & $\begin{array}{l}\text { West China Hospital + Sichuan } \\
\text { University }\end{array}$ & Phase 2 & $\begin{array}{c}\text { Phase 1: } \\
\text { ChiCTR2000037518 } \\
\begin{array}{c}\text { NCT04530656 } \\
\text { Phase 2: }\end{array} \\
\text { ChiCTR2000039994 } \\
\begin{array}{c}\text { NCT04640402 } \\
\text { NCT04718467 }\end{array}\end{array}$ \\
\hline 35 & Protein subunit & $\begin{array}{l}\text { IMP CoVac-1 (SARS-CoV-2 } \\
\text { HLA-DR peptides) }\end{array}$ & $\begin{array}{c}1 \text { dose } \\
\text { Day 0 } \\
\text { Subcutaneous }\end{array}$ & University Hospital Tuebingen & Phase 1 & NCT04546841 \\
\hline 36 & Protein subunit & $\begin{array}{l}\text { UB-612 (Multitope peptide } \\
\text { based S1-RBD-protein based } \\
\text { vaccine) }\end{array}$ & $\begin{array}{c}2 \text { doses } \\
\text { Day } 0+\text { Day } 28 \\
\text { Intramuscular }\end{array}$ & $\begin{array}{c}\text { COVAXX }+ \text { United Biomedical } \\
\text { Inc }\end{array}$ & Phase 2/3 & $\begin{array}{c}\text { Phase 1: } \\
\text { NCT04545749 } \\
\text { Phase 2: } \\
\text { NCT04773067 } \\
\text { Phase 2/3: } \\
\text { NCT04683224 } \\
\end{array}$ \\
\hline 37 & Viral vector (Replicating) & $\begin{array}{l}\text { DelNS1-2019-nCoV-RBD-OPT1 } \\
\text { (Intranasal flu-based-RBD) }\end{array}$ & $\begin{array}{c}2 \text { doses } \\
\text { Day } 0+\text { Day } 28 \\
\text { Intranasal }\end{array}$ & $\begin{array}{l}\text { University of Hong Kong, } \\
\text { Xiamen University and Beijing } \\
\text { Wantai Biological Pharmacy }\end{array}$ & Phase 2 & $\begin{array}{c}\text { Phase 1: } \\
\text { ChiCTR2000037782 } \\
\text { NCT04809389 } \\
\text { Phase 2: } \\
\text { ChiCTR2000039715 } \\
\end{array}$ \\
\hline 38 & RNA based vaccine & LNP-nCoVsaRNA & $\begin{array}{c}2 \text { doses } \\
\text { Day } 0+\text { Day } 28 \\
\text { Intranasal }\end{array}$ & Imperial College London & Phase 1 & $\begin{array}{c}\text { Phase 1: } \\
\text { ISRCTN17072692 }\end{array}$ \\
\hline 39 & RNA based vaccine & $\begin{array}{l}\text { SARS-CoV-2 mRNA vaccine } \\
\text { (ARCoV) }\end{array}$ & $\begin{array}{c}2 \text { doses } \\
\text { Day } 0+\text { Day } 28 \\
\text { Intranasal }\end{array}$ & $\begin{array}{l}\text { Academy of Military Science } \\
\text { (AMS), Walvax Biotechnology } \\
\text { and Suzhou Abogen } \\
\text { Biosciences }\end{array}$ & Phase 2 & $\begin{array}{c}\text { Phase 1: } \\
\text { ChiCTR2000034112 } \\
\text { ChiCTR2000039212 } \\
\text { Phase 2: } \\
\text { ChiCTR2100041855 } \\
\end{array}$ \\
\hline
\end{tabular}


Table 3. Cont

\begin{tabular}{|c|c|c|c|c|c|c|}
\hline Number & Vaccine Platform & Type of Candidate VACCINE & Usage & Developer & Clinical Status & Phase Trials Registration No. \\
\hline 40 & Virus like particle & $\begin{array}{l}\text { Coronavirus-Like Particle } \\
\text { COVID-19 (CoVLP) }\end{array}$ & $\begin{array}{c}2 \text { doses } \\
\text { Day } 0+\text { Day } 21 \\
\text { Intranasal }\end{array}$ & Medicago Inc. & Phase $2 / 3$ & $\begin{array}{c}\text { Phase 1: } \\
\text { NCT04450004 } \\
\text { Phase 2: } \\
\text { NCT04662697 } \\
\text { Phase 2/3: } \\
\text { NCT04636697 } \\
\end{array}$ \\
\hline 41 & $\begin{array}{c}\text { Viral vector (Replicating) + } \\
\text { APC }\end{array}$ & $\begin{array}{l}\text { Covid-19/aAPC vaccine. The } \\
\text { Covid-19/aAPC vaccine is } \\
\text { prepared by applying lentivirus } \\
\text { modification with immune } \\
\text { modulatory genes and the viral } \\
\text { minigenes to the artificial } \\
\text { antigen presenting cells } \\
\text { (aAPCs). }\end{array}$ & $\begin{array}{l}3 \text { doses } \\
\text { Day } 0+\text { Day } 14+\text { Day } 28 \\
\text { Subcutaneous }\end{array}$ & $\begin{array}{l}\text { Shenzhen Geno-Immune } \\
\text { Medical Institute }\end{array}$ & Phase 1 & $\begin{array}{c}\text { Phase 1: } \\
\text { NCT04299724 } \\
\end{array}$ \\
\hline 42 & $\begin{array}{l}\text { Viral vector (Non-replicating) + } \\
\text { APC }\end{array}$ & $\begin{array}{l}\text { LV-SMENP-DC vaccine. } \\
\text { Dendritic cells are modified } \\
\text { with lentivirus vectors } \\
\text { expressing Covid-19 minigene } \\
\text { SMENP and immune } \\
\text { modulatory genes. CTLs are } \\
\text { activated by LV-DC presenting } \\
\text { Covid-19 specific antigens. }\end{array}$ & $\begin{array}{c}1 \text { dose } \\
\text { Day } 0 \\
\text { Subcutaneous }\end{array}$ & $\begin{array}{l}\text { Shenzhen Geno-Immune } \\
\text { Medical Institute }\end{array}$ & Phase $1 / 2$ & $\begin{array}{c}\text { Phase 1/2: } \\
\text { NCT04276896 } \\
\end{array}$ \\
\hline 43 & Protein subunit & $\begin{array}{c}\text { AdimrSC-2f (Recombinant } \\
\text { RBD +/ - Aluminium) }\end{array}$ & No detail & Adimmune Corporation & Phase 1 & $\begin{array}{c}\text { Phase 1: } \\
\text { NCT04522089 } \\
\end{array}$ \\
\hline 44 & DNA based vaccine & $\begin{array}{l}\text { Covigenix VAX-001-DNA } \\
\text { vaccines + proteo-lipid vehicle } \\
\text { (PLV) formulation }\end{array}$ & $\begin{array}{c}2 \text { doses } \\
\text { Day } 0+\text { Day } 14 \\
\text { Intramuscular }\end{array}$ & Entos Pharmaceuticals Inc. & Phase 1 & NCT04591184 \\
\hline 45 & DNA based vaccine & $\begin{array}{l}\text { CORVax-Spike (S) Protein } \\
\text { Plasmid DNA Vaccine }\end{array}$ & $\begin{array}{c}2 \text { doses } \\
\text { Day } 0+\text { Day } 14 \\
\text { Intradermal }\end{array}$ & Providence Health \& Services & Phase 1 & $\begin{array}{c}\text { Phase 1: } \\
\text { NCT04627675 } \\
\end{array}$ \\
\hline 46 & RNA based vaccine & ChulaCov19 mRNA vaccine & $\begin{array}{c}2 \text { doses } \\
\text { Day } 0+\text { Day } 21 \\
\text { Intramuscular }\end{array}$ & Chulalongkorn University & Phase 1 & $\begin{array}{c}\text { Phase 1: } \\
\text { NCT04566276 } \\
\end{array}$ \\
\hline 47 & DNA based vaccine & $\begin{array}{l}\text { bacTRL-Spike oral DNA } \\
\text { vaccine }\end{array}$ & $\begin{array}{l}1 \text { dose } \\
\text { Day } 0 \\
\text { Oral }\end{array}$ & Symvivo Corporation & Phase 1 & $\underline{\text { NCT04334980 }}$ \\
\hline 48 & Viral Vector (Non-replicating) & $\begin{array}{c}\text { Human Adenovirus type 5: } \\
\text { hAd5 S + N vaccine (S-fusion + } \\
\text { N-ETSD) E2b-deleted Adeno }\end{array}$ & $\begin{array}{c}1-2 \text { doses } \\
\text { Day } 0+\text { day } 21 \\
\text { Subcutaneous or Oral }\end{array}$ & Immunity Bio.Inc & Phase 1 & $\begin{array}{c}\text { Phase 1: } \\
\text { NCT04591717 } \\
\text { NCT04710303 } \\
\end{array}$ \\
\hline 49 & Viral vector (Non-replicating) & $\begin{array}{c}\text { COH04S1 } \\
\text { (MVA-SARS-2-S)-Modified } \\
\text { vaccinia ankara (sMVA) } \\
\text { platform + synthetic } \\
\text { SARS-CoV-2 }\end{array}$ & $\begin{array}{c}2 \text { doses } \\
\text { Day } 0+\text { Day } 28 \\
\text { Intramuscular }\end{array}$ & $\begin{array}{l}\text { City of Hope Medical Center + } \\
\text { National Cancer Institute }\end{array}$ & Phase 1 & $\begin{array}{c}\text { Phase 1: } \\
\text { NCT04639466 } \\
\end{array}$ \\
\hline
\end{tabular}


Table 3. Cont.

\begin{tabular}{|c|c|c|c|c|c|c|}
\hline Number & Vaccine Platform & Type of Candidate VACCINE & Usage & Developer & Clinical Status & Phase Trials Registration No. \\
\hline 50 & Viral vector (Replicating) & rVSV-SARS-CoV-2-S Vaccine & $\begin{array}{c}1 \text { dose } \\
\text { Day } 0 \\
\text { Intramuscular }\end{array}$ & $\begin{array}{l}\text { Israel Institute for Biological } \\
\text { Research }\end{array}$ & Phase $1 / 2$ & $\begin{array}{c}\text { Phase 1/2: } \\
\text { NCT04608305 } \\
\end{array}$ \\
\hline 51 & $\begin{array}{c}\text { Viral vector (Replicating) }+ \\
\text { APC }\end{array}$ & $\begin{array}{l}\text { Dendritic cell vaccine } \\
\text { AV-COVID-19. A vaccine } \\
\text { consisting of autologous } \\
\text { dendritic cells loaded with } \\
\text { antigens from SARS-CVV-2, } \\
\text { with or without GM-CSF }\end{array}$ & $\begin{array}{l}1 \text { dose } \\
\text { Day } 0 \\
\text { Intramuscular }\end{array}$ & $\begin{array}{l}\text { Aivita Biomedical, Inc. } \\
\text { National Institute of Health } \\
\text { Research and Development, } \\
\text { Ministry of Health Republic of } \\
\text { Indonesia }\end{array}$ & Phase $1 / 2$ & $\begin{array}{c}\text { Phase 1: } \\
\text { NCT04690387 } \\
\text { NCT04685603 } \\
\text { Phase 1/2: } \\
\text { NCT04386252 } \\
\end{array}$ \\
\hline 52 & Live attenuated virus & COVI-VAC & $\begin{array}{c}1-2 \text { doses } \\
\text { Day } 0 \text { or Day } 0+28 \\
\text { Intranasal } \\
\end{array}$ & $\begin{array}{l}\text { Codagenix/Serum Institute of } \\
\text { India }\end{array}$ & Phase 1 & $\begin{array}{c}\text { Phase 1: } \\
\text { NCT04619628 } \\
\end{array}$ \\
\hline 53 & Protein subunit & CIGB-669 (RBD + AgnHB) & $\begin{array}{c}3 \text { doses } \\
\text { Day } 0+14+28 \text { or Day } 0+28+ \\
56 \\
\text { Intranasal }\end{array}$ & $\begin{array}{l}\text { Center for Genetic Engineering } \\
\text { and Biotechnology (CIGB) }\end{array}$ & Phase $1 / 2$ & $\begin{array}{c}\text { Phase 1/2: } \\
\text { RPCEC00000345 } \\
\end{array}$ \\
\hline 54 & Protein subunit & $\begin{array}{l}\text { CIGB-66 (RBD + aluminium } \\
\text { hydroxide) }\end{array}$ & $\begin{array}{c}3 \text { doses } \\
\text { Day } 0+14+28 \text { or Day } 0+28+ \\
56 \\
\text { Intranasal } \\
\end{array}$ & $\begin{array}{l}\text { Center for Genetic Engineering } \\
\text { and Biotechnology (CIGB) }\end{array}$ & Phase 3 & $\begin{array}{c}\text { Phase } 1 / 2: \\
\text { RPCEC00000346 } \\
\text { Phase } 3 \\
\text { RPCEC00000359 } \\
\end{array}$ \\
\hline 55 & Inactivated Virus & VLA2001 & $\begin{array}{c}2 \text { doses } \\
\text { Day } 0+\text { Day } 21 \\
\text { Intramuscular } \\
\end{array}$ & $\begin{array}{l}\text { Valneva, National Institute for } \\
\text { Health Research, United } \\
\text { Kingdom }\end{array}$ & Phase $1 / 2$ & $\begin{array}{c}\text { Phase 1/2: } \\
\text { NCT04671017 } \\
\end{array}$ \\
\hline 56 & Protein subunit & BECOV2 & $\begin{array}{c}2 \text { doses } \\
\text { Day } 0+\text { Day } 28 \\
\text { Intramuscular }\end{array}$ & Biological E. Limited & Phase $1 / 2$ & $\begin{array}{c}\text { Phase 1/2: } \\
\text { CTRI/2020/11/029032 } \\
\end{array}$ \\
\hline 57 & Viral vector (Replicating) & $\begin{array}{l}\text { AdCLD-CoV19 (adenovirus } \\
\text { vector) }\end{array}$ & $\begin{array}{c}1 \text { dose } \\
\text { Day } 0 \\
\text { Intramuscular }\end{array}$ & Cellid Co., Ltd. & Phase $1 / 2$ & $\begin{array}{c}\text { Phase 1/2: } \\
\text { NCT04666012 } \\
\end{array}$ \\
\hline 58 & DNA based vaccine & GLS-5310 & $\begin{array}{c}2 \text { doses } \\
\text { Day } 0+\text { Day } 56 \text { or Day } 0+\text { Day } \\
84 \\
\text { Intradermal } \\
\end{array}$ & GeneOne Life Science, Inc. & Phase $1 / 2$ & $\begin{array}{c}\text { Phase 1/2: } \\
\text { NCT04673149 } \\
\end{array}$ \\
\hline 59 & Protein subunit & $\begin{array}{l}\text { Recombinant Sars-CoV-2 Spike } \\
\text { protein, Aluminum adjuvanted }\end{array}$ & $\begin{array}{c}2 \text { doses } \\
\text { Day } 0+21 \\
\text { Intramuscular }\end{array}$ & $\begin{array}{l}\text { Nanogen Pharmaceutical } \\
\text { Biotechnology }\end{array}$ & Phase $1 / 2$ & $\begin{array}{c}\text { Phase 1/2: } \\
\text { NCT04683484 } \\
\end{array}$ \\
\hline 60 & Protein subunit & $\begin{array}{l}\text { Recombinant protein vaccine } \\
\text { S-268019 (using Baculovirus } \\
\text { expression vector system) }\end{array}$ & $\begin{array}{c}2 \text { doses } \\
\text { Day } 0+21 \\
\text { Intramuscular }\end{array}$ & Shionogi & Phase $1 / 2$ & $\begin{array}{c}\text { Phase 1/2: } \\
\text { jRCT2051200092 } \\
\end{array}$ \\
\hline 61 & Viral vector (Non-replicating) & $\begin{array}{l}\text { AdCOVID, Adenovirus-based } \\
\text { platform expresses the } \\
\text { receptor-binding domain (RBD) } \\
\text { of the Sars-Cov-2 spike protein }\end{array}$ & $\begin{array}{l}1 \text { doses } \\
\text { Day 0 } \\
\text { Intranasal }\end{array}$ & Altimmune, Inc. & Phase 1 & $\begin{array}{c}\text { Phase 1: } \\
\text { NCT04679909 } \\
\end{array}$ \\
\hline
\end{tabular}


Table 3. Cont.

\begin{tabular}{|c|c|c|c|c|c|c|}
\hline Number & Vaccine Platform & Type of Candidate VACCINE & Usage & Developer & Clinical Status & Phase Trials Registration No. \\
\hline 62 & Protein subunit & $\begin{array}{l}\text { SARS-CoV-2-RBD-Fc fusion } \\
\text { protein }\end{array}$ & $\begin{array}{l}\text { Dosage and Schedule not } \\
\text { specified } \\
\text { Subcutaneous or intramuscular }\end{array}$ & $\begin{array}{l}\text { University Medical Center } \\
\text { Groningen + Akston } \\
\text { Biosciences Inc. } \\
\end{array}$ & Phase $1 / 2$ & $\begin{array}{c}\text { Phase 1/2: } \\
\text { NCT04681092 } \\
\end{array}$ \\
\hline 63 & Inactivated Virus & $\begin{array}{l}\text { ERUCOV-VAC, inactivated } \\
\text { virus }\end{array}$ & $\begin{array}{c}2 \text { doses } \\
\text { Day } 0+21 \\
\text { Intramuscular }\end{array}$ & Erciyes University & Phase 2 & $\begin{array}{c}\text { Phase 1: } \\
\text { NCT04691947 } \\
\text { Phase 2: } \\
\text { NCT04824391 } \\
\end{array}$ \\
\hline 64 & Protein subunit & $\begin{array}{l}\text { COVAC-1 and COVAC-2 } \\
\text { sub-unit vaccine (spike protein) } \\
+ \text { SWE adjuvant }\end{array}$ & $\begin{array}{c}2 \text { doses } \\
\text { Day } 0+28 \\
\text { Intramuscular }\end{array}$ & University of Saskatchewan & Phase $1 / 2$ & $\begin{array}{c}\text { Phase 1/2: } \\
\text { NCT04702178 } \\
\end{array}$ \\
\hline 66 & Protein subunit & $\begin{array}{l}\text { Razi Cov Pars, recombinant } \\
\text { spike protein }\end{array}$ & $\begin{array}{c}3 \text { doses } \\
\text { Day } 0+21+51 \\
\text { Intramuscular and intranasal }\end{array}$ & $\begin{array}{l}\text { Razi Vaccine and Serum } \\
\text { Research Institute }\end{array}$ & Phase 1 & $\begin{array}{c}\text { Phase 1: } \\
\underline{\text { IRCT20201214049709N1 }}\end{array}$ \\
\hline 67 & Inactivated Virus & COVID-19 inactivated vaccine & $\begin{array}{c}2 \text { doses } \\
\text { Day } 0+14 \\
\text { Intramuscular }\end{array}$ & Shifa Pharmed Industrial Co & Phase $2 / 3$ & $\begin{array}{c}\text { Phase 1: } \\
\text { IRCT20201202049567N1 } \\
\underline{\text { IRCT20201202049567N2 }} \\
\end{array}$ \\
\hline 68 & Protein subunit & $\begin{array}{l}\text { MF59 adjuvanted SARS-CoV-2 } \\
\text { Sclamp vaccine }\end{array}$ & $\begin{array}{c}2 \text { doses } \\
\text { Day } 0+28 \\
\text { Intramuscular }\end{array}$ & The University of Queensland & Phase 1 & $\begin{array}{c}\text { Phase 1: } \\
\text { NCT04495933 } \\
\end{array}$ \\
\hline 69 & DNA based vaccine & COVIGEN & $\begin{array}{c}2 \text { doses } \\
\text { Day } 0+28 \\
\text { Intramuscular or intradermal }\end{array}$ & $\begin{array}{l}\text { University of Sydney, Bionet } \\
\text { Co., Ltd. Technovalia }\end{array}$ & Phase 1 & $\begin{array}{c}\text { Phase 1: } \\
\text { NCT04742842 } \\
\end{array}$ \\
\hline 70 & DNA based vaccine & $\begin{array}{l}\text { COVID-eVax, a candidate } \\
\text { plasmid DNA vaccine of the } \\
\text { Spike protein }\end{array}$ & $\begin{array}{l}\text { No detailed dosage schedule } \\
\text { Intramuscular }\end{array}$ & Takis + Rottapharm Biotech & Phase $1 / 2$ & $\begin{array}{c}\text { Phase 1/2: } \\
\text { NCT04788459 } \\
\text { EUCTR2020-003734-20-IT } \\
\end{array}$ \\
\hline 71 & Viral vector (Non-replicating) & $\begin{array}{l}\text { BBV154, Adenoviral vector } \\
\text { COVID-19 vaccine }\end{array}$ & $\begin{array}{c}1 \text { dose } \\
\text { Day 0 } \\
\text { Intramuscular }\end{array}$ & $\begin{array}{l}\text { Bharat Biotech International } \\
\text { Limited }\end{array}$ & Phase 1 & $\begin{array}{c}\text { Phase 1: } \\
\text { NCT04751682 } \\
\end{array}$ \\
\hline 72 & RNA based vaccine & $\begin{array}{l}\text { PTX-COVID19-B, mRNA } \\
\text { vaccine }\end{array}$ & $\begin{array}{c}2 \text { doses } \\
\text { Day } 0+28 \\
\text { Intramuscular }\end{array}$ & Providence Therapeutics & Phase 1 & $\begin{array}{c}\text { Phase 1: } \\
\text { NCT04765436 } \\
\end{array}$ \\
\hline 73 & Viral vector (Replicating) & $\begin{array}{l}\text { NDV-HXP-S, Newcastle } \\
\text { disease virus (NDV) vector } \\
\text { expressing the spike protein of } \\
\text { SARS-CoV-2, with or without } \\
\text { the adjuvant CpG } 1018\end{array}$ & $\begin{array}{c}2 \text { doses } \\
\text { Day } 0+28 \\
\text { Intramuscular }\end{array}$ & $\begin{array}{c}\text { Mahidol University; The } \\
\text { Government Pharmaceutical } \\
\text { Organization (GPO); Icahn } \\
\text { School of Medicine at Mount } \\
\text { Sinai }\end{array}$ & Phase $1 / 2$ & $\begin{array}{c}\text { Phase 1/2: } \\
\text { NCT04764422 } \\
\end{array}$ \\
\hline
\end{tabular}


Table 3. Cont

\begin{tabular}{|c|c|c|c|c|c|c|}
\hline Number & Vaccine Platform & Type of Candidate VACCINE & Usage & Developer & Clinical Status & Phase Trials Registration No. \\
\hline 74 & RNA based vaccine & $\begin{array}{l}\text { CoV2 SAM (LNP) vaccine. A } \\
\text { self-amplifying mRNA (SAM) } \\
\text { lipid nanoparticle (LNP) } \\
\text { platform + Spike antigen }\end{array}$ & $\begin{array}{c}2 \text { doses } \\
\text { Day } 0+28 \\
\text { Intramuscular }\end{array}$ & GlaxoSmithKline & Phase 1 & $\begin{array}{c}\text { Phase 1: } \\
\text { NCT04758962 } \\
\end{array}$ \\
\hline 76 & Protein subunit & $\begin{array}{l}\text { SK SARS-CoV-2 recombinant } \\
\text { surface antigen protein subunit } \\
\text { (NBP2001) + adjuvanted with } \\
\text { alum. }\end{array}$ & $\begin{array}{c}2 \text { doses } \\
\text { Day } 0+28 \\
\text { Intramuscular }\end{array}$ & SK Bioscience Co., Ltd. & Phase 1 & $\begin{array}{c}\text { Phase 1: } \\
\text { NCT04760743 } \\
\end{array}$ \\
\hline 77 & Viral vector (Non-replicating) & $\begin{array}{l}\text { Chimpanzee Adenovirus } \\
\text { serotype } 68 \text { (ChAd) and } \\
\text { self-amplifying mRNA (SAM) } \\
\text { vectors expressing spike alone, } \\
\text { or spike plus additional } \\
\text { SARS-CoV-2 T cell epitopes. }\end{array}$ & $\begin{array}{c}2-3 \text { doses } \\
\text { Day } 0+14+28 \text { or Day } 0+28+ \\
56 \text { or } \\
\text { Day } 0+112 \\
\text { Intramuscular }\end{array}$ & Gritstone Oncology & Phase 1 & $\begin{array}{c}\text { Phase 1: } \\
\text { NCT04776317 } \\
\end{array}$ \\
\hline 78 & RNA based vaccine & $\begin{array}{l}\text { mRNA-1273.351. A lipid } \\
\text { nanoparticle } \\
\text { (LNP)-encapsulated } \\
\text { mRNA-based vaccine that } \\
\text { encodes for a full-length, } \\
\text { prefusion stabilized S protein of } \\
\text { the SARS-CoV-2 B.1.351 } \\
\text { variant. }\end{array}$ & $\begin{array}{c}3 \text { doses } \\
\text { Day } 0+28+56 \\
\text { Intramuscular }\end{array}$ & $\begin{array}{l}\text { Moderna + National Institute } \\
\text { of Allergy and Infectious } \\
\text { Diseases (NIAID) }\end{array}$ & Phase 1 & $\begin{array}{c}\text { Phase 1: } \\
\text { NCT04785144 } \\
\end{array}$ \\
\hline 79 & Protein subunit & $\begin{array}{c}\text { SpFN (spike ferritin } \\
\text { nanoparticle) uses spike } \\
\text { proteins with a liposomal } \\
\text { formulation QS22 (ALFQ) } \\
\text { adjuvant. } \\
\end{array}$ & $\begin{array}{c}3 \text { doses } \\
\text { Day } 0+28+120 \\
\text { Intramuscular }\end{array}$ & $\begin{array}{l}\text { Walter Reed Army Institute of } \\
\text { Research (WRAIR) }\end{array}$ & Phase 1 & $\begin{array}{c}\text { Phase 1: } \\
\text { NCT04784767 } \\
\end{array}$ \\
\hline 80 & Protein subunit & $\begin{array}{l}\text { EuCorVac-19; A spike protein } \\
\text { using the recombinant protein } \\
\text { technology and with an } \\
\text { adjuvant. }\end{array}$ & $\begin{array}{c}2 \text { doses } \\
\text { Day } 0+21 \\
\text { Intramuscular }\end{array}$ & $\begin{array}{l}\text { POP Biotechnologies and } \\
\text { EuBiologics Co.,Ltd }\end{array}$ & Phase $1 / 2$ & $\begin{array}{c}\text { Phase 1/2: } \\
\text { NCT04783311 } \\
\end{array}$ \\
\hline 81 & Inactivated virus & $\begin{array}{c}\text { Inactivated SARS-CoV-2 } \\
\text { vaccine FAKHRAVAC (MIVAC) }\end{array}$ & $\begin{array}{c}2 \text { doses } \\
\text { Day } 0+21 \\
\text { Intramuscular }\end{array}$ & $\begin{array}{l}\text { Organization of Defensive } \\
\text { Innovation and Research }\end{array}$ & Phase 1 & $\begin{array}{c}\text { Phase 1: } \\
\text { IRCT20210206050259N1 }\end{array}$ \\
\hline 82 & Live attenuated virus & $\begin{array}{l}\text { MV-014-212, a live attenuated } \\
\text { vaccine that expresses the spike } \\
\text { (S) protein of SARS-CoV-2 }\end{array}$ & $\begin{array}{l}2 \text { doses } \\
\text { Day } 0+35 \\
\text { Intranasal }\end{array}$ & Meissa Vaccines, Inc. & Phase 1 & $\begin{array}{c}\text { Phase 1: } \\
\text { NCT04798001 } \\
\end{array}$ \\
\hline
\end{tabular}


Table 3. Cont

\begin{tabular}{|c|c|c|c|c|c|c|}
\hline Number & Vaccine Platform & Type of Candidate VACCINE & Usage & Developer & Clinical Status & Phase Trials Registration No. \\
\hline 83 & RNA based vaccine & $\begin{array}{l}\text { MRT5500, an mRNA vaccine } \\
\text { candidate }\end{array}$ & $\begin{array}{c}2 \text { doses } \\
\text { Day } 0+21 \\
\text { Intramuscular }\end{array}$ & $\begin{array}{l}\text { Sanofi Pasteur and Translate } \\
\text { Bio }\end{array}$ & Phase $1 / 2$ & $\begin{array}{c}\text { Phase 1/2: } \\
\text { NCT04798027 }\end{array}$ \\
\hline 84 & Virus like particle & SARS-CoV-2 VLP Vaccine & $\begin{array}{c}1 \text { doses } \\
\text { Day } 0 \\
\text { Subcutaneous }\end{array}$ & $\begin{array}{c}\text { The Scientific and } \\
\text { Technological Research Council } \\
\text { of Turkey }\end{array}$ & Phase 1 & $\begin{array}{c}\text { Phase 1: } \\
\text { NCT04818281 } \\
\end{array}$ \\
\hline 85 & Protein subunit & $\begin{array}{l}\text { ReCOV: Recombinant } \\
\text { two-component spike and RBD } \\
\text { protein COVID-19 vaccine } \\
\text { (CHO cell). }\end{array}$ & $\begin{array}{c}2 \text { doses } \\
\text { Day } 0+21 \\
\text { Intramuscular }\end{array}$ & Jiangsu Rec-Biotechnology & Phase 1 & $\begin{array}{c}\text { Phase 1: } \\
\text { NCT04818801 } \\
\end{array}$ \\
\hline
\end{tabular}




\section{BiONTech (BNT162b1 and BNT162b2)}

The BiONTech trials focus on two candidates: BNT162b1 and BNT162b2. Both vaccines are lipid-based, nucleoside-modified mRNA vaccines that encode the trimerized receptorbinder (RBD) of the spike glycoprotein SARS-CoV-2. The RBD-IgG concentrations and SARS-CoV-2 neutralizing titres were measured after complete course of the vaccines. In the trial of BNT162b112, serum IgG geometric mean concentra-tion (GMC) of the recipient after first dose was comparable to the convalescent sera of COVID-19 patient. The trial showed a strong, dose-dependent vaccine-induced antibody response: the GMC of vaccine recipients is 8 times and 42 times the convalescent sera in the $10 \mu \mathrm{g}$ and $30 \mu \mathrm{g}$ group, respectively. A further increase to $100 \mu \mathrm{g}$ showed no additional elevation of RBD IgG concentration, compared with $10 \mu \mathrm{g}$ and $30 \mu \mathrm{g}$ trials [4,5].

BNT162b1 induced functional $\mathrm{CD}^{+}$and $\mathrm{CD}^{+} \mathrm{T}$ cell responses in almost all recipients: 95.2\% participants mounted RBD-specific $\mathrm{CD}^{+} \mathrm{T}$ cell responses. There is a positive correlation between RBD-binding IgG and SARS-CoV-2 neutralizing antibody titres [6]. Severe adverse events, such as grade 3 decrease of lymphocyte count and grade 2 neutropenia, were manageable. No clinical deteriorations were observed.

The overall serological responses of BNT162b2 and BNT162b1 were similar [7]: Phase 2/3 trial showed they conferred 94.6\% (95\% CI 89.7-97.3) protection against COVID-19 in persons older than 16 years of age [8]. Double dose vaccination further boosts the immune response in both younger and older adults, while the response was weaker in participants 65 to 85 years old. Exploration of dose elevations of vaccinations in the elderly should be conducted in future research.

Serious adverse events such as death from arteriosclerosis and cardiac arrest, paroxysmal ventricular arrhythmia were recorded. However, cardiovascular events occurred similarly in the placebo group, with two deaths due to haemorrhagic stroke and myocardial infarction, and two with unknown causes. It is uncertain whether the vaccine increases cardiovascular risk.

COVID-19 infections is associated with a higher inflammatory burden that can induce vascular inflammation, myocarditis and cardiac arrhythmias [17]. Vaccinations for other acute respiratory virus infection show the possibility of a transient increase in the risk of vascular events [18]. Some studies showed a 10-fold increase of acute myocardial infarction admission within the seven days for of testing positive for influenza B, and a 5-fold increase of risk with influenza A [41-43]. Another study suggests that binding of SARS-CoV-2 to ACE2 can cause acute myocardial and lung injury through the alteration in ACE2 signaling pathways [44]. The effect of vaccinations for patients with pre-existing cardiovascular diseases have to be further elucidated.

\section{Moderna (mRNA1273)}

mRNA1273 is manufactured by Moderna. It encodes stabilized prefusion S-2P antigen, consisting of the SARS-CoV-2 glycoprotein with a transmembrane anchor and an intact S1-S2 cleavage site [9]. A preliminary report showed the binding antibody IgG GMT to S-2P increased after vaccinations, with $100 \%$ serocon-version rates by day 15 . Doseresponse relationship was observed with higher dosage eliciting stronger IgG GMT. Both low dose $(25 \mu \mathrm{g})$ and medium dose $(100 \mu \mathrm{g})$ elicited $\mathrm{CD}^{+} \mathrm{T}$ cell responses by expression of Th1 cytokines.

The phase 1 clinical trial showed a dose-response relationship [45]. It also elicited a strong CD4 ${ }^{+}$cytokine response involving Th1 helper T cells. The higher dosage $(100 \mu \mathrm{g})$ was chosen for phase 3 clinical trials. Robust neutralizing activity to the $614 \mathrm{G}$ variant was observed for the $100 \mu \mathrm{g}$ dose, regardless of the patients' age.

The phase 3 clinical trial showed 94.1\% (95\% CI 89.3-96.8; $p<0.001$ ) protective efficacy in preventing COVID-19 illness [10]. The vaccine efficacy to prevent COVID-19 was consistent across subgroups stratified by age ( 18 to $<65$ years of age and $\geq 65$ years), presence of risk for severe COVID-19, sex, and race and ethnic groups. The frequency 
of grade 3 adverse events in the placebo group (1.3\%) was similar to that in the vaccine group (1.5\%).

\section{ChadOx1 nCoV-19 (AZD1222)}

ChadOx1 nCoV-19 consists of replication-deficient simian adenovirus vector ChAdOx1, containing the full-length structural surface glycoprotein of SARS-CoV-2, with a tissue plasminogen activator leader sequence [12]. It expresses a codon-optimised coding sequence for the spike protein. Upon vaccination, antibodies against SARS-CoV-2 spike protein peaked by day 28 and remained elevated up to day 56 in participants receiving 1 dose. The median titre of the booster-dose group was more than five times higher than the single-dose group. Paracetamol was used to reduce local regional side effects such as fever and myalgia. Prophylactic paracetamol was prescribed in certain participants, but serological response was independent of prophylactic paracetamol prescription.

ChAdOx1 nCoV-19 appears to be better tolerated in older adults than in younger adults, and it provides similar immunogenicity across all age groups after a booster dose [13]. Serological response was independent of dosage and age after booster, with the IgG level being consistently higher than those without booster vaccinations. Median IgG titres peaked by day 42 in most groups who received two-dose vaccinations. A higher vaccine efficacy was observed when the participants first received a low-dose followed by a stand-ard-dose $(90 \%, 95 \%$ CI $67.4-97.0, p=0.01)$, compared with two standard-dose recipients (62.1\%, 95\% CI 41.0-75.7) [24].

In terms of safety profile, 13 serious adverse events occurred but none was considered related to either study vaccine as assessed by the investigators [13]. There was a reported case of hemolytic anemia and three cases of transverse myelitis. The independent neurological committee considered two of them were unlikely to be related to vaccination, and one of them was an idiopathic, short segment spinal cord demyelination [14].

Phase 3 trials are being performed in the United Kingdom, Brazil and the United States of America to assess the protective efficacy and safety [13].

Various thromboembolic events were reported after participants have received ChadOx1 nCoV-19 (AZD122) vaccinations. One of the reasons may be related to post-vaccination immune-mediated thrombo-cytopenia [46]. In a report including 28 patients after receiving AZD122 with thromboembolic events, all of them were tested positive for anti-platelet factor 4(PF4)-heparin antibodies, which clinically mimics auto-immune heparin-induced thrombocytopenia [47]. This was similarly observed in another study where five participants with thromboembolic events (100\%) tested positive with high level of IgG anti-PF4polyanion complexes, measured by enzyme linked immunoassay (ELISA) [48]. The adverse reaction may be related to the adenovirus-platelet-leukocyte complexes formed after vaccination, which are taken up by the liver by interaction [28] with membrane-associated heparan sulphate proteoglycan (MAHSP) [49,50]. MAHSP acts as a receptor for viral entry. Heparin can lead to dose-dependent inhibition of this reaction, leading to induction of anti-PF4/heparin antibodies [51]. Subsequently, heparin-induced thrombocytopenia and thrombophilia was observed in patients after receiving AZD122 vaccination.

\section{Convidecia (Adenovirus Type-5 Vectored COVID-19 Vaccine)}

Adenovirus type-5 (AD-5) vectored COVID-19 vaccine is a replication of defective Ad5-vectored vaccine expressing the spike glycoprotein SARS-CoV-2 [15]. It clones an optimized full-length spike gene based on Wuhan-Hu-1 with the tissue plasminogen activator signal peptide gene into an E1 and E3 deleted Ad-5 vector, and constructed the Ad- 5 vectored COVID-19 vaccines using the Admax system. The vaccine demonstrated a dose-response relationship at day 28 after vaccination: the T-cell responses in the high dose group were significantly higher than that in the low-dose group $(p<0.0010)$, but not significant compared with that in the middle group. TNF- $\alpha$ expression from $\mathrm{CD} 4^{+} \mathrm{T}$ cells was significantly lower in the low dose group than in the high dose $(p<0.0001)$ and middle dose groups $(p=0.0032)$. TNF- $\alpha$ expression from $C D 8^{+} \mathrm{T}$ cells was higher in the 
high-dose group than that in both the middle dose group $(p=0.016)$ and the low-dose group $(p<0.0001)$.

The phase two trial showed a higher dosage correlates with a higher seroconversion rate and higher GMTs of neutralizing antibody responses to pseudovirus [16]. The seroconversion rate in high-dose group was 59\% (95\% CI 52-65) and $47 \%(95 \%$ CI $39-56)$. The GMT were 61.4 (95\% CI 53.0-71.0) in the high-dose group and 55.3 (95\% CI 45.3-67.5) in the low dose group. Stratified analysis based on age showed older adults ( $>55$ years) were associated with lower antibody responses in both dose groups post-vaccinations. A total of 25 grade 3 or above adverse events were documented, but they were self-limiting and resolved within 3 to 4 days without medications.

Phase 3 trial are being performed globally, with 40,000 participants. It is expected to be completed by January 2022 [17].

\section{Gam-COVID-Vac (Recombinant Adenovirus Type 26 and Recombinant Adenovirus Type 5 Vaccine)}

rAd26-S and rAD5-S are vaccines made by Russian manufacturer which carry the gene for SARS-CoV-2 full-length glycoprotein S. Phase 1/2 studies showed both rAd26-S and rAD5-S formulations were safe and well tolerated [18]. Patients receiving combined rAD26$\mathrm{S}$ and rAD5-S were associated with a higher se-roconversion rate $(100 \%)$ and neutralising antibody GMT (49.25) on day 28 [19]. Combined regimen was better than individual rAD26-S or rAD5-S injection. Increased $\mathrm{CD}^{+} \mathrm{T}$ cells, $\mathrm{CD} 8^{+} \mathrm{T}$ cells and IFN- $\gamma$ secre-tion were observed in all vaccine recipients. No serious adverse events were reported.

The phase 3 study showed a protective efficacy of 91.6\% (95\% CI 85.6-95.2) against COVID-19 [19]. Immunogenicity was significantly higher in the vaccination arm: The RBD-specific IgG was detected in 98\% participant samples, with a GMT of 8996 (95\% CI 7610-10,635) and a seroconversion rate of $98.25 \%$. Conversely, the RBD-specific IgG was detected in 15\% participant samples with a GMT of 30.55 (95\% CI 20.18-46.26) and a seroconversion rate of $14.91 \%$ ( $p<0.0001 \mathrm{vs.}$. the vaccination arm). Neutralising antibody follows a similar trend too: with GMT of 44.5 (95\% CI 31.8-62.2) and seroconversion rate of $95.83 \%$ in the vaccination arm; compared with GMT of 1.6 (95\% CI 1.12-2.19) and $7.14 \%$ seroconversion rate.

\section{Covovax (NVAX-CoV2373)}

NVAX-CoV2373 is a recombinant SARS-CoV-2 nanoparticle vaccine composed of trimeric full-length sARS-CoV-2 spike glycoproteins and Matrix-M1 adjuvant. The phase 1 study showed two-dose $5 \mu \mathrm{g}$ regimen with adjuvant induced IgG GMT and neutralization responses that exceeded convalescent serum from most symptomatic COVID-19 patients [20]. The immunological outcomes in $5 \mu \mathrm{g}$ and $25 \mu \mathrm{g}$ vaccination groups were comparable. Second vaccinations with adjuvant resulted in GMT level four times greater than the convalescent plasma in symptomatic patients. Adjuvant regimens induced polyfunctional $\mathrm{CD} 4^{+}$T-cell responses that were reflected in IFN- $\gamma$, TNF- $\alpha$ and IL-2 production on spike protein stimulation. No serious adverse events were reported. Interim analysis showed the vaccine achieved protective efficacy of $86 \%$ against UK variant and $60 \%$ against South Africa variant [21]. The phase 3 trial showed a protective efficacy of $89.3 \%$ (95\% CI 75.2-95.4) against B.1.1.7 UK variant, but only 49.4\% (95\% CI 6.1-72.8) against B.1.351 variant [22].

\section{WIV04-Strain Inactivated SARS-CoV-2 Vaccine}

The WIV-04 strain inactivated SARS-CoV-2 vaccine is designed by the Wuhan Institute of Biological Products Co Ltd. The WIV-04 strain was isolated and cultivated in a Verco cell line for propagation, and the supernatant of the infected cells was inactivated by $\beta$-propiolactone. Interim analysis of two randomised controlled trials showed a seroconversion rate of $100 \%$ in phase 1 trial and $85.7 \%$ in the phase 2 trial [10]. A lower-dosage injection was associated with a higher GMT of neutralizing antibody at day 14 after the third injection, compared with other dosage groups. Injection schedule on day 0 and 
21 confer a higher GMT, compared with the schedule of day 0 and 14. Most patients started to generate antibody response after the second injection, and remained at high level 14 days after the third injection. The most common adverse reactions were injection site pain and fever, which were mild and self-limiting. The phase 3 study data was not available at the time of writing.

\section{BBIBP-CorV}

BBIBP-CorV is developed by the Beijing Institute of Biological Products. It is an inactivated vaccine developed from the strain 19nCoV-CDC-Tan-HB02 (HB02) [11]. The HB02 strain was purified and passaged in Vero cell lines to generate vaccine production by using a novel carrier in a basket reactor. In the phase 1 trial, a higher dosage $(8 \mu \mathrm{g})$ was associated with a higher seroconversion rate by day 14 , while seroconversion rates reached $100 \%$ in all three dosage cohorts on day 28 . By day 28 , the neutralizing antibody GMT was significantly higher in the high-dose group than the low-dose group $(2 \mu \mathrm{g})$, with no significant difference between medium-dose $(4 \mu \mathrm{g})$ and high-dose. Younger adults were associated with higher neutralizing anti-body GMT, compared with older adults (>60 years).

The phase 2 trial showed the immunization schedule of $4 \mu \mathrm{g}$ on day 0 and 21 was associated with the highest neutralizing antibody GMT (282.7, 95\% CI 221.2-361.4), compared with other immunization schedules. One grade 3 or above adverse event was documented due to self-limiting grade 3 fever $\left(>38.5^{\circ} \mathrm{C}\right)$.

A phase 3 study is currently underway in Abu Dhabi with 15,000 participants: 5000 participants receiving placebo, another 5000 receiving BBIBP-CorV, and the remaining 5000 receiving another inactivated vaccine manufacturer by Sinopharm [23].

\section{Coronavac Vaccine}

Coronavac is developed by Sinovac Life Sciences (Beijing China) as an inactivated vaccine created from Vero cells that have been inoculated with SARS-CoV-2 (CN02 strain) [24]. The phase 1 trial showed seroconversion rates of $88 \%$ and $100 \%$ and $8 \%$ in the $3 \mu \mathrm{g}, 6 \mu \mathrm{g}$ and placebo groups on day 28, respectively. The neutralising antibody GMT were 465.8 (95\% CI 288.1-753.1), 1395.9 (95\% CI, 955.2-2039.7) and 89.8 (95\%CI 76.1-105.9) in the three groups, respectively. Higher dosage was associated with a better immunogenicity.

The phase 2 immunization schedule trial showed receiving vaccination on day 0 and 14 resulted in the most promising outcomes: seroconversion rates were $97 \%, 100 \%$ and $0 \%$ in the $3 \mu \mathrm{g}, 6 \mu \mathrm{g}$ and placebo groups on day 28 , respectively. The neutralising antibody GMT were 44.1 (95\% CI 37.2-52.2), 65.4 (95\% CI 56.4-75.9) and 2.0 (95\% CI 2.0-2.1) in the three groups, respectively. One case of serious adverse events related to acute hypersensitivity with presentation of urticaria $48 \mathrm{~h}$ after the first dose. It was managed with chlorphenamine and dexamethasone, and recovered within 3 days.

The phase 3 study data has not been published in medical journals. An online search of the phase 3 study in Brazil showed a $50.4 \%$ protective efficacy in preventing symptomatic infections, $78 \%$ protective efficacy in preventing mild cases requiring treatment and $100 \%$ prevention of severe cases [52]. Phase 3 studies in Turkey and Indonesia showed a protective efficacy of $83.5 \%$ and $65.3 \%$, respectively $[53,54]$.

\section{Ad26.COV2.S}

Ad26.COV2.S is developed by Johnson \& Johnson. It is a recombinant, replicationincompetent adenovirus serotype 26 (Ad26) vector encoding a full-length and stabilized SARS-CoV-2 spike protein. Early animal studies showed promising efficacy with low-dose single-shot vaccination $[25,26]$. In the phase 1 clinical trial, binding and neutralizing antibodies were detected in $100 \%$ of vaccine recipients by 57 days after single vaccinations [27]. The geometric mean titres (GMT) of spike-specific binding antibodies and neutralizing antibodies ranged from 2432-5729 and 242-449, respectively. A booster immunization on day 57 increased binding antibody titres and neutralizing antibody titres by a mean 
of 2.56-fold (range 1.58-3.04) and 4.62-fold (range: 3.56-5.68), respectively. An interim study showed the titres remain stable until at least day 71 [28]. Strong immune responses were recorded as $\mathrm{CD}^{+} \mathrm{T}$ cells were detected in 76 to $83 \%$ of the young patients (aged $18-55$ years), and 60 to $67 \%$ in older patients (aged greater than 65). Phase 3 data showed a $66.9 \%(95 \%$ CI 59.0-73.4) protective efficacy across all participant age groups, and $76.3 \%$ ( $95 \% \mathrm{CI}, 61.6-86.0)$ in participants older than 60 years old [29]. In preventing severe or critical COVID-19, Ad26.COV2.S was associated with $76.7 \%$ efficacy at 14 days, and $85.4 \%$ at 28 days. Adverse reactions were recorded such as thromboembolic events (15 in vaccination arm and 10 in placebo arm) and tinnitus (6 vs. 0 ).

Subgroup analysis based on region showed a higher vaccine efficacy in N. America, compared with South Africa and Latin America. The protective efficacies were 74.4\% (95\% CI $65.0-81.6)$ at 14 days and $72.0 \%$ (95\% CI 58.2-81.7) at 28 days; compared with $52.0 \%$ (95\% CI 30.3-67.4) at day 14 and 64\% (95\% CI 41.2-87.7) in South Africa. The protective efficacies in Latin America were 64.7\% (95\% CI 54.1-73.0) and 61.0\% (95\% CI 46.9-71.8), respectively. This may be related to the difference in the prevalence of mutant strain of SARS-CoV-2 in different regions.

\section{Covaxin (BBV 152)}

BBV 152 is a whole-viron inactivated SARS-CoV-2 vaccine formulated with a toll-like receptor $7 / 8$ agonist molecule (IMDG) adsorbed to alum (Algel) [30]. It is developed by Bharat Biotech from an isolated NIV-2020-770 strain of a patient with COVID-19 sequenced in India. Previous animal studies showed acceptable safety profiles, humoral and cellmediated responses [31]. Phase 2 trials showed a good reactogenicity, safety profile, and enhanced humoral and cell-mediated immune responses when participants received a higher dose $(6 \mu \mathrm{g})$ of Algel-IMDG formulation [32]. In the phase 2 trial, the GMT at day 56 was significantly higher in the $6 \mu \mathrm{g}$ group (197.0, 95\% CI 155.6-249.4) compared with the $3 \mu$ group $(100.9,95 \%$ CI 74.7-137.4, $p=0.0041)$. Seroconversion rates were $92.9 \%$ (95\% CI 88.2-96.2) in the $3 \mu \mathrm{g}$ group, and $98.3 \%$ (95\% CI 95.1-99.6) in the $6 \mu \mathrm{g}$ group. The Algel-IMDG formulation elicited T-cell responses biased to a Th1 phenotype at day 42 , with no significant difference in causing local or systemic adverse reactions between the $3 \mu \mathrm{g}$ and the $6 \mu \mathrm{g}$ groups. No serious adverse events were reported in the study. Protective efficacy was not reported.

\section{Challenges}

In view of the surging infections and promising efficacy in clinical trials of vaccines (Table 2), many countries have advocated vaccination programs for their citizens. However, questions have been raised concerning the efficacy against new variant strains. Experience in Manaus (Brazil) showed secondary immunity alone was not sufficient to arrest transmission [55], possibly due to new variant strains. The B.1.1.7 of the UK and South African 501Y.V2 variants are shown to cause alterations to the spike protein, which may affect immune recognition of antibodies derived from existing vaccines [56]. Further clinical trials are required to test for the efficacy of existing vaccines against mutant variants.

Another problem is the duration of the protective efficacy. It is likely that at least yearly boosters are necessary. Seasonal modification to annual vaccines to arrest the transmission of previous strains may also be considered. It is also doubtful whether circulating neutralizing antibody is protective against COVID-19 infection as animal studies showed robust viral infective activities in nasal turbinate. Reinfection is still potentially possible [57].

Also with the expansion of the vaccination programs in the general population, the relationship of certain side effects, such as the thrombotic events occurring after receiving ChadOx1 nCoV-19, with the vaccines has to be further determined.

The pathological correlation between incidence of cardiovascular adverse events and vaccination with in-activated or live-attenuated virus has to be elucidated. SARS-CoV-2 infection is associated with systemic inflammatory response causing cytokine releases and 
cytokine storm, resulting in vasculopathy and its complications [58]. Likewise, influenzae carries similar pathogenesis as SARS-CoV-2. However, the experience of influenzae vaccinations (inactivated virus) shows that vaccinations reduced major cardiovascular events significantly, and has become part of the routine care of patients with chronic cardiovascular conditions [59]. COVID-19 vaccinations do not follow the typical trend of influenzae. In general, attenuated patho-gens have the very rare potential to revert to its pathogenic form [60]. Further studies is required to determine whether vaccines with inactivated SARS-CoV-2 can reduce or induce cardiovascular events.

Diabetic patients are associated with a higher risk of inflammatory response and coagulopathy during an infection episode [61]. Close monitoring of inflammatory markers, tight glycemic controls and lifestyle modifications are recommended for diabetic COVID-19 care [62]. Acute complications after vaccinations can be monitored by measurement of prognostic inflammatory markers, such as serum ferritin, lactate dehydrogenase, C-reactive protein (CRP), erythrocyte sedimentation rate, D-dimer level, cardiac troponin and $\mathrm{N}$ terminal pro-brain-type natriuretic peptide (NT-proBNP) [63-66]. These markers have close associations with the prognosis of COVID-19 infections. However, the interval and duration of monitoring has to be further studied. The relation between thrombotic events and vaccine using as adenovirus vector has been discussed in a previous section.

\section{Conclusions}

The COVID-19 vaccines in clinical trials have all shown promising immunogenicity with varying degree of protective efficacy, and an acceptable safety profile. A second dose immunization gives more robust immune response in all vaccines. The immunological outcome in the elderly is poorer than in the younger recipients. Further exploration on immunization schedule is required, such as more frequent vaccinations or higher dosage in each injection. Grade 3 or above side effects are not common in the clinical trials to date.

Author Contributions: Literature search, study designs, figures, data collections, data analysis, data interpretation and manuscript writing were done by Z.-P.Y., M.Y. and C.-L.L., Z.-P.Y. and M.Y. contributed equally to this work. All authors have read and agreed to the published version of the manuscript.

Funding: The authors did not receive funding for this project.

Institutional Review Board Statement: Not applicable.

Informed Consent Statement: Not applicable.

Data Availability Statement: The data generated during and/or analysed during the current study are available on electronic databases (PubMed, Embase, Medline, Google Scholar, Cochrane). All data generated or analysed during this study are included in this published article.

Conflicts of Interest: The authors Zhipeng Yan, Ming Yang and Ching-Lung Lai declare there is no conflict of interest.

\section{References}

1. World Health Organization. Weekly Epidemiology Update 23 February 2021. WHO Situation Report. 2021. Available online: https:/ / www.who.int/publications/m/item/weekly-epidemiological-update---23-february-2021 (accessed on 25 March 2021).

2. Bonam, S.R.; Kotla, N.G.; Bohara, R.A.; Rochev, Y.; Webster, T.J.; Bayry, J. Potential immuno-nanomedicine strategies to fight COVID-19 like pulmonary infections. Nano Today 2021, 36, 101051. [CrossRef] [PubMed]

3. Pardi, N.; Hogan, M.J.; Weissman, D. Recent advances in mRNA vaccine technology. Curr. Opin. Immunol. 2020, 65, 14-20. [CrossRef] [PubMed]

4. Mulligan, M.J.; Lyke, K.E.; Kitchin, N.; Absalon, J.; Gurtman, A.; Lockhart, S.; Neuzil, K.; Raabe, V.; Bailey, R.; Swanson, K.A.; et al. Phase I/II study of COVID-19 RNA vaccine BNT162b1 in adults. Nature 2020, 586, 589-593. [CrossRef] [PubMed]

5. Sahin, U.; Muik, A.; Derhovanessian, E.; Vogler, I.; Kranz, L.M.; Vormehr, M.; Baum, A.; Pascal, K.; Quandt, J.; Maurus, D.; et al. COVID-19 vaccine BNT162b1 elicits human antibody and TH1 T-cell responses. Nature 2020, 586, 594-599. [CrossRef]

6. Sette, A.; Moutaftsi, M.; Moyron-Quiroz, J.; McCausland, M.M.; Davies, D.H.; Johnston, R.J.; Peters, B.; Benhnia, M.R.-E.-I.; Hoffmann, J.; Su, H.-P.; et al. Selective CD4+ T Cell Help for Antibody Responses to a Large Viral Pathogen: Deterministic Linkage of Specificities. Immunnology 2008, 28, 847-858. [CrossRef] 
7. Walsh, E.E.; Frenck, R.W.; Falsey, A.R.; Kitchin, N.; Absalon, J.; Gurtman, A.; Lockhart, S.; Neuzil, K.; Mulligan, M.J.; Bailey, R.; et al. Safety and Immunogenicity of Two RNA-Based Covid-19 Vaccine Candidates. N. Engl. J. Med. 2020, 383, 2439-2450. [CrossRef]

8. Polack, F.P.; Thomas, S.J.; Kitchin, N. Safety and Efficacy of the BNT162b2 mRNA Covid-19 Vaccine. N. Engl. J. Med. 2020, 383, 2603-2615. [CrossRef]

9. Jackson, L.A.; Anderson, E.J.; Rouphael, N.G. An mRNA Vaccine against SARS-CoV-2-Preliminary Report. N. Engl. J. Med. 2020, 383, 1920-1931. [CrossRef]

10. Xia, S.; Duan, K.; Zhang, Y. Effect of an Inactivated Vaccine Against SARS-CoV-2 on Safety and Immuno-genicity Outcomes: Interim Analysis of 2 Randomized Clinical Trials. JAMA 2020, 324, 951-960. [CrossRef] [PubMed]

11. Xia, S.; Zhang, Y.; Wang, Y. Safety and immunogenicity of an inactivated SARS-CoV-2 vaccine, BBIBP-CorV: A randomised, double-blind, placebo-controlled, phase $1 / 2$ trial. Lancet Infect. Dis. 2021, 21, 39-51. [CrossRef]

12. Folegatti, P.M.; Ewer, K.J.; Aley, P.K. Safety and immunogenicity of the ChAdOx1 nCoV-19 vaccine against SARS-CoV-2: A preliminary report of a phase 1/2, single-blind, randomised controlled trial. Lancet 2020, 396, 467-478. [CrossRef]

13. Ramasamy, M.N.; Minassian, A.M.; Ewer, K.J.; Flaxman, A.L.; Folegatti, P.M.; Owens, D.R.; Voysey, M.; Aley, P.K.; Angus, B.; Babbage, G.; et al. Safety and immunogenicity of ChAdOx1 nCoV-19 vaccine administered in a prime-boost regimen in young and old adults (COV002): A single-blind, randomised, controlled, phase 2/3 trial. Lancet 2020, 396, 1979-1993. [CrossRef]

14. Voysey, M.; Clemens, S.A.C.; Madhi, S.A. Safety and efficacy of the ChAdOx1 nCoV-19 vaccine (AZD1222) against SARS-CoV-2: An interim analysis of four randomised controlled trials in Brazil, South Africa, and the UK. Lancet 2021, 397, 99-111. [CrossRef]

15. Zhu, F.C.; Li, Y.H.; Guan, X.H. Safety, tolerability, and immunogenicity of a recombinant adenovi-rus type-5 vectored COVID-19 vaccine: A dose-escalation, open-label, non-randomised, first-in-human trial. Lancet 2020, 395, 1845-1854. [CrossRef]

16. Zhu, F.-C.; Guan, X.-H.; Li, Y.-H.; Huang, J.-Y.; Jiang, T.; Hou, L.-H.; Li, J.-X.; Yang, B.-F.; Wang, L.; Wang, W.-J.; et al. Immunogenicity and safety of a recombinant adenovirus type-5-vectored COVID-19 vaccine in healthy adults aged 18 years or older: A randomised, double-blind, placebo-controlled, phase 2 trial. Lancet 2020, 396, 479-488. [CrossRef]

17. ClinicalTrials.Gov. Phase III Trial of A COVID-19 Vaccine of Adenovirus Vector in Adults 18 Years Old and Above. Available online: https: / / clinicaltrials.gov/ct2/show/NCT04526990 (accessed on 18 March 2021).

18. Logunov, D.Y.; Dolzhikova, I.V.; Zubkova, O.V. Safety and immunogenicity of an rAd26 and rAd5 vector-based heterologous prime-boost COVID-19 vaccine in two formulations: Two open, non-randomised phase 1/2 studies from Russia. Lancet 2020, 396, 887-897. [CrossRef]

19. Logunov, D.Y.; Dolzhikova, I.V.; Shcheblyakov, D.V. Safety and efficacy of an rAd26 and rAd5 vector-based heterologous prime-boost COVID-19 vaccine: An interim analysis of a randomised con-trolled phase 3 trial in Russia. Lancet 2021, 397, 671-681. [CrossRef]

20. Keech, C.; Albert, G.; Cho, I. Phase 1-2 Trial of a SARS-CoV-2 Recombinant Spike Protein Nano-particle Vaccine. N. Engl. J. Med. 2020, 383, 2320-2332. [CrossRef]

21. Mahase, E. Covid-19: Novavax vaccine efficacy is $86 \%$ against UK variant and $60 \%$ against South African variant. BMJ 2021, 372 , n296. [CrossRef]

22. Taylor, N.P. Novavax COVID-19 vaccine $90 \%$ efficacious in phase 3, but protection plummets against one variant. 2021. Available online: https: / / www.fiercebiotech.com/biotech/novavax-covid-19-vaccine-90-efficacious-phase-3-but-protection-plummetsagainst-one-variant (accessed on 9 April 2021).

23. Chakraborty, S.; Mallajosyula, V.; Tato, C.M.; Tan, G.S.; Wang, T.T. SARS-CoV-2 vaccines in advanced clinical trials: Where do we stand? Adv. Drug Deliv. Rev. 2021, 172, 314-338. [CrossRef]

24. Zhang, Y.; Zeng, G.; Pan, H. Safety, tolerability, and immunogenicity of an inactivated SARS-CoV-2 vaccine in healthy adults aged 18-59 years: A randomised, double-blind, placebo-controlled, phase 1/2 clinical trial. Lancet Infect. Dis. 2021, 21, 181-192. [CrossRef]

25. Anadolu Agency. Decision Based on Results of Country's Phase III Trials That Put Estimated Vaccine Efficacy at 65.3\%, Says Official. Available online: https:/ / www.astrazeneca.com/media-centre/press-releases/2021/azd1222-us-phase-iii-primaryanalysis-confirms-safety-and-efficacy.html (accessed on 18 March 2021).

26. Mercado, N.B.; Zahn, R.; Wegmann, F. Single-shot Ad26 vaccine protects against SARS-CoV-2 in rhesus macaques. Nature 2020, 586, 583-588. [CrossRef] [PubMed]

27. He, X.; Chandrashekar, A.; Zahn, R.; Wegmann, F.; Yu, J.; Mercado, N.B.; McMahan, K.; Martinot, A.J.; Piedra-Mora, C.; Beecy, S.; et al. Low-Dose Ad26.COV2.S Protection Against SARS-CoV-2 Challenge in Rhesus Macaques. bioRxiv 2021. [CrossRef]

28. Stephenson, K.E.; Le Gars, M.; Sadoff, J.; de Groot, A.M.; Heerwegh, D.; Truyers, C.; Atyeo, C.; Loos, C.; Chandrashekar, A.; McMahan, K.; et al. Immunogenicity of the Ad26.COV2.S Vaccine for COVID-19. JAMA 2021. [CrossRef]

29. Sadoff, J.; Le Gars, M.; Shukarev, G.; Heerwegh, D.; Truyers, C.; De Groot, A.M.; Stoop, J.; Tete, S.; Van Damme, W.; Leroux-Roels, I.; et al. Interim Results of a Phase 1-2a Trial of Ad26.COV2.S Covid-19 Vaccine. New Engl. J. Med. 2021. [CrossRef]

30. Yadav, P.D.; Ella, R.; Kumar, S.; Patil, D.R.; Mohandas, S.; Shete, A.M.; Vadrevu, K.M.; Bhati, G.; Sapkal, G.; Kaushal, H.; et al. Immunogenicity and protective efficacy of inactivated SARS-CoV-2 vaccine candidate, BBV152 in rhesus macaques. Nat. Commun. 2021, 12, 1-11. [CrossRef] 
31. Ella, R.; Vadrevu, K.M.; Jogdand, H.; Prasad, S.; Reddy, S.; Sarangi, V.; Ganneru, B.; Sapkal, G.; Yadav, P.; Abraham, P.; et al. Safety and immunogenicity of an inactivated SARS-CoV-2 vaccine, BBV152: A double-blind, randomised, phase 1 trial. Lancet Infect. Dis. 2021, 21, 637-646. [CrossRef]

32. Ella, R.; Vadrevu, K.M.; Jogdand, H.; Prasad, S.; Reddy, S.; Sarangi, V.; Ganneru, B.; Sapkal, G.; Yadav, P.; Abraham, P.; et al. Safety and immunogenicity of an inactivated SARS-CoV-2 vaccine, BBV152: Interim results from a double-blind, random-ised, multicentre, phase 2 trial, and 3-month follow-up of a double-blind, randomised phase 1 trial. Lancet Infect. Dis. 2021. [CrossRef]

33. Porter, K.R.; Raviprakash, K. DNA Vaccine Delivery and Improved Immunogenicity. Curr. Issues Mol. Biol. 2017, 22, 129-138. [CrossRef]

34. Li, L.; Petrovsky, N. Molecular mechanisms for enhanced DNA vaccine immunogenicity. Expert Rev. Vaccines 2016, 15, 313-329. [CrossRef]

35. Suschak, J.J.; Williams, J.A.; Schmaljohn, C.S. Advancements in DNA vaccine vectors, non-mechanical delivery methods, and molecular adjuvants to increase immunogenicity. Hum. Vaccines Immunother. 2017, 13, 2837-2848. [CrossRef]

36. Liu, M.A. A Comparison of Plasmid DNA and mRNA as Vaccine Technologies. Vaccines 2019, 7, 37. [CrossRef]

37. Ritchie, H.; Beltekian, D.; Mathieu, E.; Hasell, J.; Macdonald, B.; Giattino, C.; Appel, C.; Roser, M.; Yunits, B.; van Woerden, E.; et al. Statistics and Research: Coronavirus (COVID-19) Vaccinations. 2021. Available online: https://ourworldindata.org/covidvaccinations (accessed on 22 March 2021).

38. Liu, X.; Liu, C.; Liu, G.; Luo, W.; Xia, N. COVID-19: Progress in diagnostics, therapy and vaccination. Theranostics 2020, 10, 7821-7835. [CrossRef] [PubMed]

39. Karpinski, T.M.; Ozarowski, M.; Seremak-Mrozikiewicz, A.; Wolski, H.; Wlodkowic, D. The 2020 race to-wards SARS-CoV-2 specific vaccines. Theranostics 2021, 11, 1690-1702. [CrossRef] [PubMed]

40. World Health Organization Solidarity Vaccines Trial Expert Group. Draft Landscape and Tracker of COVID-19 Candidate Vaccines; WHO: Geneva, Switzerland, 2021.

41. Madjid, M.; Safavi-Naeini, P.; Solomon, S.D.; Vardeny, O. Potential Effects of Coronaviruses on the Cardiovascular System: A Review. JAMA Cardiol. 2020, 5, 831-840. [CrossRef] [PubMed]

42. Smeeth, L.; Thomas, S.L.; Hall, A.J.; Hubbard, R.; Farrington, P.; Vallance, P. Risk of Myocardial Infarction and Stroke after Acute Infection or Vaccination. New Engl. J. Med. 2004, 351, 2611-2618. [CrossRef] [PubMed]

43. Kwong, J.C.; Schwartz, K.L.; Campitelli, M.A. Acute Myocardial Infarction after Laboratory-Confirmed Influenza Infection. N. Engl. J. Med. 2018, 378, 345-353. [CrossRef]

44. Soumya, R.S.; Unni, T.G.; Raghu, K.G. Impact of COVID-19 on the Cardiovascular System: A Review of Available Reports. Cardiovasc. Drugs Ther. 2020, 1-15. [CrossRef] [PubMed]

45. Anderson, E.J.; Rouphael, N.G.; Widge, A.T. Safety and Immunogenicity of SARS-CoV-2 mRNA-1273 Vaccine in Older Adults. N. Engl. J. Med. 2020, 383, 2427-2438. [CrossRef] [PubMed]

46. Andreas Greinacher, T.T.; Theodore, E.; Warkentin, K.W.; Kyrle, P.; Eichinger., S. A Prothrombotic Thrombocytopenic Disorder Resembling Heparin-Induced Thrombocytopenia Following Coronavirus-19 Vaccination. N. Engl. J. Med. 2021. [CrossRef]

47. Greinacher, A.; Thiele, T.; Warkentin, T.E.; Weisser, K.; Kyrle, P.A.; Eichinger, S. Thrombotic Thrombocytopenia after ChAdOx1 nCov-19 Vaccination. N. Engl. J. Med. 2021. [CrossRef]

48. Schultz, N.H.; Sørvoll, I.H.; Michelsen, A.E.; Munthe, L.A.; Lund-Johansen, F.; Ahlen, M.T.; Wiedmann, M.; Aamodt, A.-E.; Skattør, T.H.; Tjønnfjord, G.E.; et al. Thrombosis and Thrombocytopenia after ChAdOx1 nCoV-19 Vaccination. N. Engl. J. Med. 2021. [CrossRef] [PubMed]

49. Shayakhmetov, D.M.; Gaggar, A.; Ni, S.; Li, Z.-Y.; Lieber, A. Adenovirus Binding to Blood Factors Results in Liver Cell Infection and Hepatotoxicity. J. Virol. 2005, 79, 7478-7491. [CrossRef] [PubMed]

50. Baker, A.H.; Mcvey, J.H.; Waddington, S.N.; Di Paolo, N.C.; Shayakhmetov, D.M. The Influence of Blood on In Vivo Adenovirus Bio-distribution and Transduction. Mol. Ther. 2007, 15, 1410-1416. [CrossRef] [PubMed]

51. Summerford, C.; Samulski, R.J. Membrane-Associated Heparan Sulfate Proteoglycan Is a Receptor for Adeno-Associated Virus Type 2 Virions. J. Virol. 1998, 72, 1438-1445. [CrossRef] [PubMed]

52. News Reuters. UPDATE 2-China's Sinovac Defends COVID-19 Vaccine after Disappointing Brazil Data. Available online: https:/ / www.reuters.com/article/health-coronavirus-malaysia-idCNL1N2JO0O9 (accessed on 18 March 2021).

53. Tavsan, S. Sinovac's COVID-19 Shot is 83\% Effective, Not 91\%, Turkey Says. Nikkei Asia. Available online: https://asia.nikkei. com/Spotlight/Coronavirus/COVID-vaccines/Sinovac-s-COVID-19-shot-is-83-effective-not-91-Turkey-says (accessed on 9 April 2021).

54. Nupus, H. Indonesia Approves China's CoronaVac for Emergency Use. 2020. Available online: https://www.aa.com.tr/en/asiapacific/indonesia-approves-china-s-coronavac-for-emergency-use/2105881 (accessed on 9 April 2021).

55. U.S. Food and Drug Administration. FDA Briefing Document. In Proceedings of the Vaccines and Related Biological Products Advisory Committee Meeting, 11 December 2020; Available online: https:/ / papers.ssrn.com/sol3/papers.cfm?abstract_id=3747 047 (accessed on 25 March 2021).

56. Janssen Ad26.COV2.S. In Proceedings of the Vaccine for the Prevention of COVID-19. 26 February 2021. Available online: https:/ / www.fda.gov/advisory-committees/advisory-committee-calendar/vaccines-and-related-biological-productsadvisory-committee-february-26-2021-meeting-announcement (accessed on 25 March 2021). 
57. Buss, L.F.; Prete, C.A.; Abrahim, C.M.M. Three-quarters attack rate of SARS-CoV-2 in the Brazilian Amazon during a largely unmitigated epidemic. Science 2021, 371, 288-292. [CrossRef]

58. Callaway, E. Could new COVID variants undermine vaccines? Labs scramble to find out. Nat. Cell Biol. 2021, 589, 177-178. [CrossRef]

59. Zhou, D.; Chan, J.F.; Zhou, B. Robust SARS-CoV-2 infection in nasal turbinates after treatment with systemic neutralizing antibodies. Cell Host Microbe. 2021, 29, 551-563. [CrossRef]

60. Clerkin, K.J.; Fried, J.A.; Raikhelkar, J.; Sayer, G.; Griffin, J.M.; Masoumi, A.; Jain, S.S.; Burkhoff, D.; Kumaraiah, D.; Rabbani, L.; et al. COVID-19 and Cardiovascular Disease. Circulation 2020, 141, 1648-1655. [CrossRef] [PubMed]

61. Ho, J.S.Y.; Tambyah, P.A.; Sia, C.-H. A Call for Vaccine Against COVID-19: Implications for Cardiovascular Morbidity and Healthcare Utilization. Cardiovasc. Drugs Ther. 2020, 34, 585-587. [CrossRef]

62. World Health Organization. Module 2: Types of Vaccine and Adverse Reactions. Available online: https://vaccine-safetytraining.org/live-attenuated-vaccines.html (accessed on 23 March 2021).

63. Guo, W.; Li, M.; Dong, Y.; Zhou, H.; Zhang, Z.; Tian, C.; Qin, R.; Wang, H.; Shen, Y.; Du, K.; et al. Diabetes is a risk factor for the progression and prognosis of COVID-19. Diabetes/Metab. Res. Rev. 2020, 36, e3319. [CrossRef] [PubMed]

64. Katulanda, P.; Dissanayake, H.A.; Ranathunga, I.; Ratnasamy, V.; Wijewickrama, P.S.A.; Yogendranathan, N.; Gamage, K.K.K.; De Silva, N.L.; Sumanatilleke, M.; Somasundaram, N.P.; et al. Prevention and management of COVID-19 among patients with diabetes: An appraisal of the literature. Diabetology 2020, 63, 1440-1452. [CrossRef]

65. Chen, C.; Yan, J.T.; Zhou, N.; Zhao, J.P.; Wang, D.W. Analysis of myocardial injury in patients with COVID-19 and association between concomitant cardiovascular diseases and severity of COVID-19. Zhonghua Xin Xue Guan Bing Za Zhi 2020, 48, E008.

66. Anderson, R.M.; Vegvari, C.; Truscott, J.; Collyer, B.S. Challenges in creating herd immunity to SARS-CoV-2 infection by mass vaccination. Lancet 2020, 396, 1614-1616. [CrossRef] 